Check for updates

Cite this: RSC Adv., 2018, 8, 24188

Received 28th April 2018 Accepted 24th June 2018 DOI: $10.1039 / c 8 r a 03666 g$ rsc.li/rsc-advances

\section{Current knowledge and development of hederagenin as a promising medicinal agent: a comprehensive review}

\author{
Jia Zeng, (iD ${ }^{\text {ab }}$ Ting Huang, (D) ${ }^{\mathrm{b}}$ Man Xue, ${ }^{\mathrm{b}}$ Jianxing Chen, ${ }^{\mathrm{b}}$ Linglin Feng, ${ }^{\star b}$ Ruofei Du*a \\ and Yi Feng*a
}

Hederagenin (HG) is a pentacyclic triterpenoid that exists in many plants in the form(s) of sapogenin or saponins. This review highlights the pharmacokinetics, pharmacological activities, mechanisms of action, and safety of HG using literature and patents from the last 50 years to collate information on this compound as a promising medicinal agent. This review also looks at the development of related derivatives of HG with increased efficacy and lower toxicity. HG is quickly absorbed in the gastrointestinal tract with a short elimination half-life, and can cross the blood-brain barrier and rapidly distribute into cerebrospinal fluid. HG has been shown to possess a wide range of pharmacological activities, including anti-tumor, antiinflammatory, anti-depressant, anti-neurodegenerative, anti-hyperlipidemia, anti-diabetic, anti-leishmanial, and anti-viral activity. In particular, the extensive anti-tumor activity indicates that HG has the potential to be a highly effective chemotherapy agent. Recently, in the search for more active compounds as potential pharmaceuticals, structural modification of the triterpene scaffold of HG at the C-3, C-12, C-13, C-23, and C-28 positions, has resulted in compounds that exhibited greater potency than HG itself. However, the low bioavailability and moderate hemolysis effect of HG may limit its clinical application. The cause of the observed toxic effects in some animals, including dogs, cats, cattle, goats, and horses also needs to be explained. Future studies of HG focusing on extending the half-life, improving bioavailability, enhancing pharmacological activity, as well as decreasing or avoiding hemolysis by structural modification or formulation design could potentially accelerate HG from the preclinical to clinical research phase.
${ }^{a}$ Shanghai University of Traditional Chinese Medicine, Shanghai 201203, PR China. E-mail:drf790101@163.com; fyi@vip.sina.com

${ }^{b}$ Key Laboratory of Contraceptives and Devices Research (NPFPC), Shanghai Engineering Research Center of Reproductive Health Drug and Devices, Shanghai
Institute of Planned Parenthood Research, Shanghai 200032, PR China. E-mail: fenglinglinxin@163.com

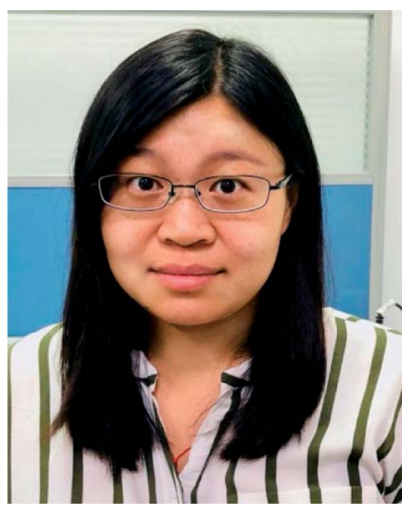

Jia Zeng is working as a research assistant in Drug Research Department of Shanghai Institute of Planned Parenthood Research, Key Laboratory of Contraceptives and Devices Research, and Shanghai Engineering Research Center of Reproductive Health Drug and Devices, China. She received her master's degree in Shanghai University of Traditional Chinese Medicine in 2010. Currently, she is studying for her PhD in Shanghai University of Traditional Chinese Medicine. Her research interests mainly focus on novel drug delivery systems and key technologies of traditional Chinese medicine preparations.

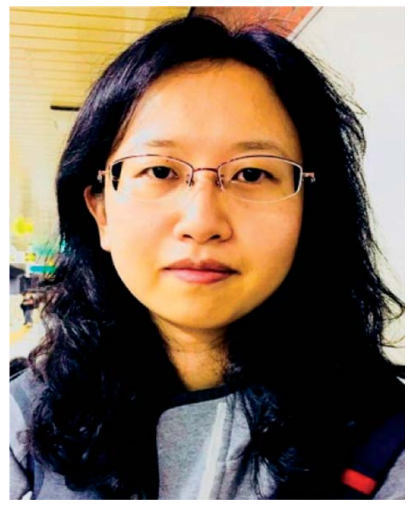

Ting Huang is working in Drug Research Department of Shanghai Institute of Planned Parenthood Research as an associate researcher. She is also the academic secretary of Shanghai Engineering Research Center of Reproductive Health Drug and Devices. She received her MSc degree in Shenyang Pharmaceutical University in 2009. Her mainly interests are $A D M E / T$ of new drugs, construction of drug delivery systems and research on mechanisms of natural drugs. 


\section{Introduction}

Natural products have made great contributions to drug development; ${ }^{1}$ classic examples include artemisinin for malaria and paclitaxel for the treatment of cancer. Hederagenin (HG), also called caulosapogenin or melanthigenin, was first discovered in the seeds of English ivy in 1849 and is an oleanane-type triterpene saponin. ${ }^{2} \mathrm{HG}$ is found in a variety of traditional medicines as an abundant aglycone and occurs in particularly high levels in the food product quinoa. ${ }^{3}$ In addition, HG acts as a chemotaxonomic marker for plants of the Sapindaceae family. ${ }^{4}$ In recent years, HG has been observed to be biologically active, as well as many other saponins with similar structures, such as ursolic acid and corosolic acid. HG exhibits multiple pharmaceutical and biological activities, including antitumor, ${ }^{2,5-23}$ anti-inflammatory, ${ }^{24-30}$ anti-depressant, ${ }^{31-35}$ antineurodegenerative, ${ }^{36-38}$ anti-hyperlipidemia, ${ }^{4,39,40}$ anti-

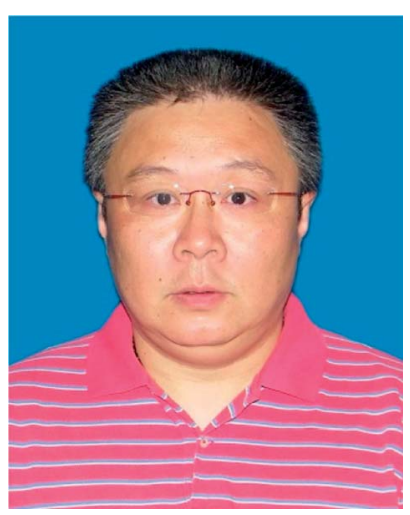

Professor Jianxing Chen is the director of Drug Research Department in Shanghai Institute of Planned Parenthood Research, the deputy director of the National Population and Family Planning Key Laboratory of Contraceptives Drugs and Devices Research, and the managing deputy director of Shanghai Engineering Research Center of Reproductive Health Drug and Devices, China. He received his bachelor's degree in medicinal chemistry in East China University of science and technology in 1987. His research interests mainly focus on synthesis of prostaglandin drugs and steroid drugs, and development of long-acting contraceptive drugs and devices.

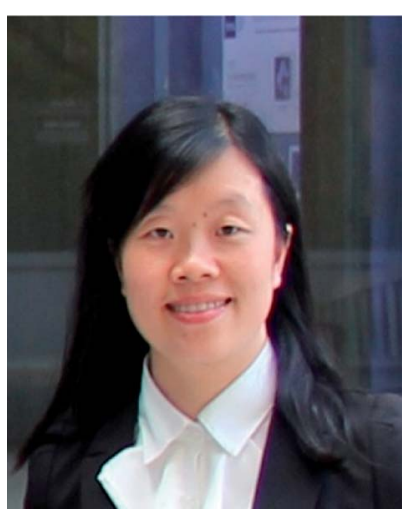

Linglin Feng, PhD, is a Professor of Pharmaceutics in Shanghai Institute of Planned Parenthood Research in China. She also serves as a key member of the State Key Laboratory of Contraceptive Drugs and Devices, National Population and Family Planning; and committee member of Pharmaceutics in Shanghai Pharmaceutical Association, China. She got her BS and MS with a focus in pharmaceutics and quality standards from Shenyang Pharmaceutical University before receiving her PhD degree in Pharmaceutical Science from Fudan University. Her researches mainly focus on controlled/sustained release system, targeting drug delivery systems and biodegradable drug delivery systems. diabetic, ${ }^{\mathbf{4 1 - 4 3}}$ anti-leishmanial, ${ }^{\mathbf{1 9 , 4 4 , 4 5}}$ and anti-viral (against hepatitis B) activity. ${ }^{46}$ Recently, a number of studies have investigated the use of $\mathrm{HG}$ as a potential anti-tumor agent. ${ }^{5,6,10-12,14-16}$ The pharmacokinetics, ${ }^{47-51}$ structural modification, ${ }^{17-21,35,38,45,46}$ and mechanisms of action $^{4-6,10-16,19,25,26,31-34,36,37,39,40,43,45}$ of HG have also been studied. However, possibly owing to limited in vivo data, HG is still in the preclinical development stage. This paper comprehensively summarizes the current progress of the research and development of HG, including its sources, structure and properties, pharmacokinetics, pharmacological activities, and safety, through a systematic review of previously published literature and patents from last 50 years (Fig. 1). The aim of this review is to improve the current knowledge and development capacity of HG, to encourage the development of more potent candidate drugs from its derivatives for potential clinical applications.

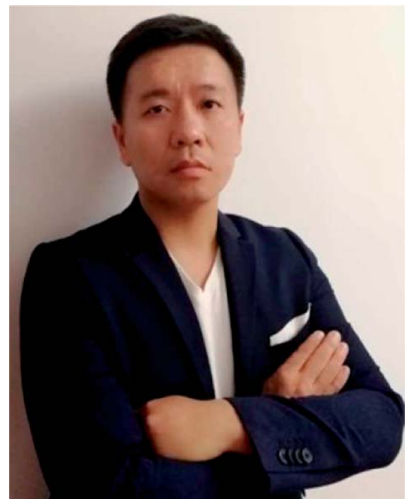

Dr. Ruofei Du is working as an associate researcher in Shanghai University of Traditional Chinese Medicine. He received his doctor degree of science of Chinese materia medica in Shanghai University of Traditional Chinese Medicine in 2014. He has published 23 academic papers and has 6 patents authorized. His research interests mainly focus on new technologies of traditional Chinese medicine preparations, computational pharmaceutics, and development of new drugs of traditional Chinese medicine and health products.

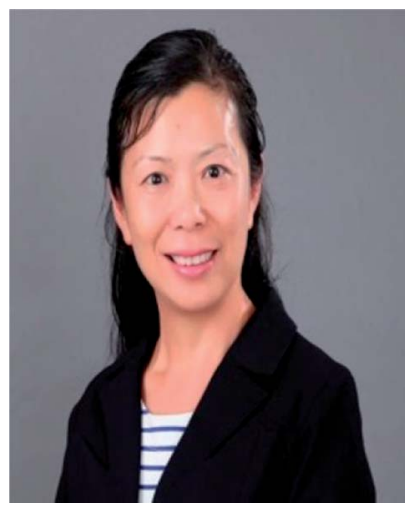

Dr Yi Feng is a professor of Shanghai University of Traditional Chinese Medicine, and she is the director of Engineering Research Center of Modern Preparation Technology of Traditional Chinese Medicine of Ministry of Education. She has worked as the 10th and 11th committee members of the Chinese Pharmacopoeia Committee, and a review expert on new traditional Chinese drugs of CFDA. She has taken on research of key projects of national and provincial levels. Her research interests mainly focus on key technologies and basic theories of traditional Chinese medicine preparations. 


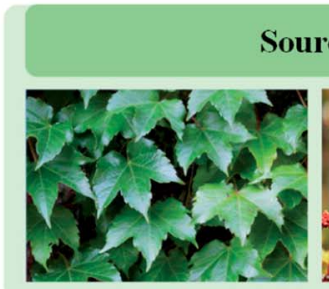

Sources
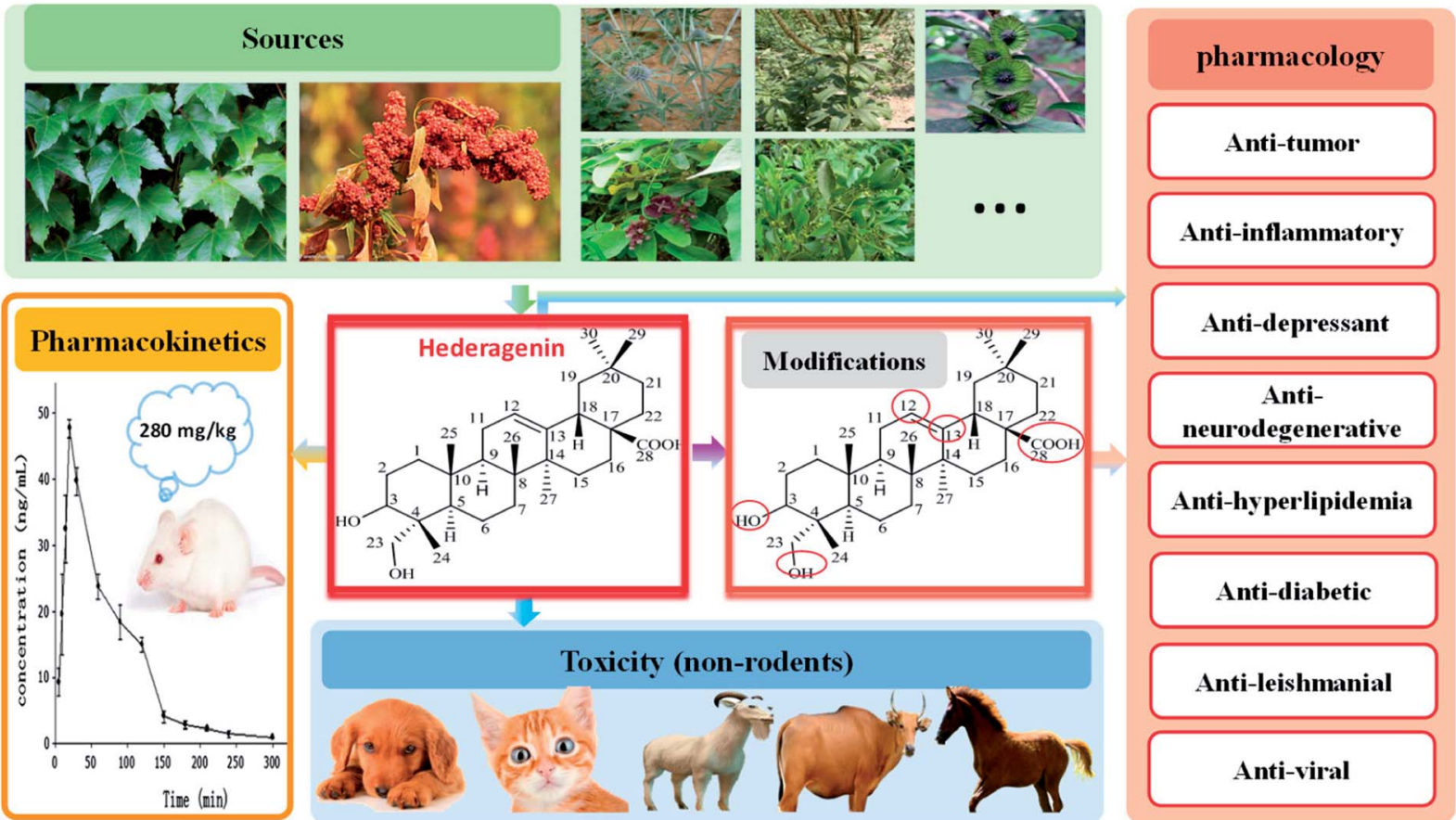

Fig. 1 Overview of sources, pharmacokinetics, pharmacology and toxicity of hederagenin.

\section{Sources}

HG was first found in the leaves of English ivy (Hedera helix L., a species of flowering plant of the family Araliaceae, native to most of Europe and western Asia) from which it derived its name. ${ }^{52} \mathrm{HG}$ has since been identified as the active constituent in many plants, from various sources, which are known to be used as traditional medicines, such as the fruit of Fructus Akebiae (from species of the Akebiae genera, in particular quinata, a traditional Chinese medicine called "Ba Yue Zha"), ${ }^{31,47}$ the leaves of Cyclocarya paliurus (commonly referred to as the "sweet tea tree", which is mainly distributed in the southern provinces of China and is a traditional Chinese herb historically used to clear toxins), ${ }^{6}$ the fruit of Sapindus saponaria L. (popularly known in Brazil as soldier soap and soapmaker, found principally in South America and India), ${ }^{53}$ the roots of Clematis mandshurica Ruprecht (a medicinal plant widely cultivated in Asia), ${ }^{26}$ and other natural sources. Table 1 lists the sources and distribution of HG in some plants.,5,624-27,31,41,42,54-70

However, the most practical source of HG may be the food product known as quinoa, which has a particularly high content of HG glycosides ${ }^{3,71}$ in the flowers, fruit, seeds (the edible portion $^{72}$ is $27-28 \%$ total saponins or $307.8-465 \mathrm{mg}$ per $100 \mathrm{~g}$ dry weight, inclusive of all glycosides ${ }^{73}$ ) and seed coat. ${ }^{74}$ Quinoa has a highly regarded reputation as the "mother of all grains" with a history of being eaten and planted for over 5000-7000 years in South America and south-central Mexico. ${ }^{75}$ Studies have shown that quinoa is the only single plant that meets all the basic nutritional requirements for the human body. ${ }^{75-77}$ The globally recognized public health authority, the Food and Agriculture Organization of the United Nations endorses quinoa as the most suitable entire nutritional food for humans. Other glycones of HG include $\alpha$-hederin and hederacoside C from Hedera helix ${ }^{52}$ asperosaponin IV from Dipsacus asper, ${ }^{\mathbf{5 0 , 7 8}}$ SMG-1 from Sapindus mukorossi Gaertn., ${ }^{79}$ macranthoside B from Lonicera macranthoides ${ }^{\mathbf{8 0}}$ and kalopanaxsaponin A from Kalopanax pictus Nakai. ${ }^{\mathbf{1}}$

\section{Structure and properties}

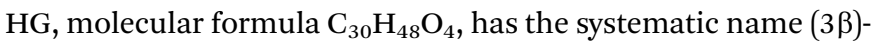
3,23-dihydroxyolean-12-en-28-oic acid. Structurally, it is a naturally occurring pentacyclic triterpene sapogenin bearing a hydroxyl group at the $\mathrm{C}-3$ position and a hydroxymethyl group at the C-23 position in ring $\mathrm{A}$, a double bond at the $\mathrm{C}-12$ and $\mathrm{C}$ 13 positions in ring $\mathrm{C}$, and a carboxylate group at the $\mathrm{C}-28$ position in ring $\mathrm{E}$ (Fig. 2). ${ }^{82}$ Chemical modifications at these positions are known to have an impact on the biological activity of HG and most research has been focused on modifications at the $\mathrm{C}-28$ position. HG is an aglycone (without sugar) and is present in other molecules where sugar moieties are bound to the structure. These glycosides may be converted to HG in the body after digestion or hydrolysis to remove the sugar molecules from the structure. ${ }^{\mathbf{8 3 , 8 4}}$

HG is a fine white crystalline powder and is odorless with a bitter taste. It is highly insoluble in water and slightly soluble in methanol and ethanol. The insolubility and poor absorption of HG means that it has low bioavailability in vivo, which may limit its clinical applications. Other physical and chemical properties of HG are summarized in Table $2 .^{85}$

\section{Pharmacokinetics}

Knowledge of the pharmacokinetics of HG is useful to explain and predict a variety of events related to the efficacy and toxicity of HG preparations. Several analytical methods have been 
Table 1 Sources and distribution of hederagenin in some plants

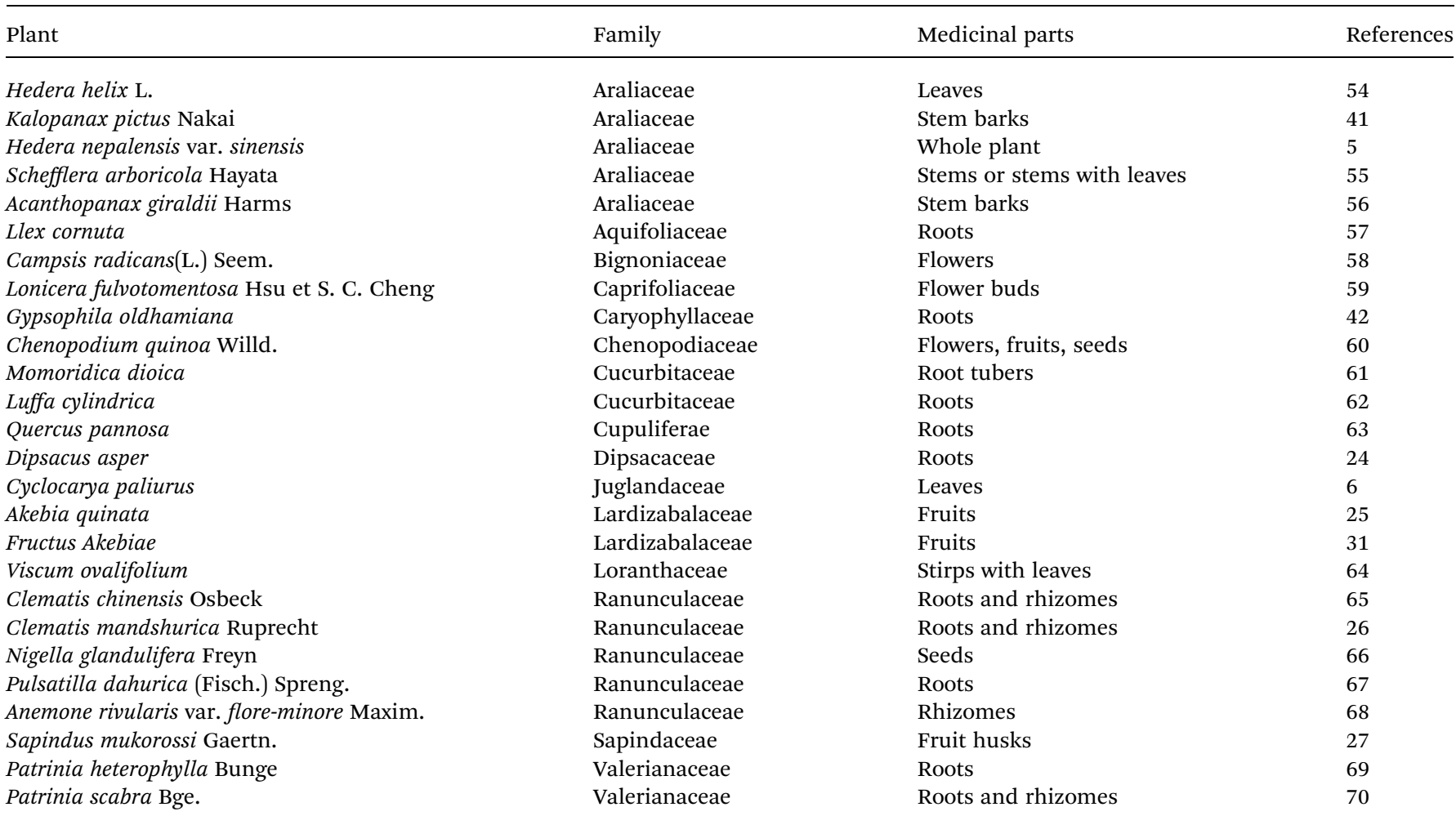

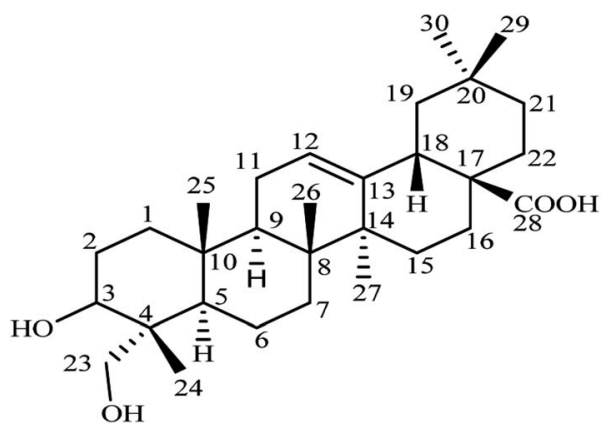

Fig. 2 Chemical structure of hederagenin.

developed and validated for the determination of HG in rats, either alone or simultaneously with HG-based saponins, for pharmacokinetic investigations after a single oral administration. ${ }^{47-51}$ The bioanalytical methods for the determination of HG

Table 2 Physical and chemical properties of hederagenin

\begin{tabular}{ll}
\hline Properties & Values \\
\hline Molecular weight & $472.70 \mathrm{~g} \mathrm{~mol}^{-1}$ \\
Melt point & $331-333{ }^{\circ} \mathrm{C}$ \\
Density & $1.14 \mathrm{~g} \mathrm{~cm}^{-3}$ \\
Boiling point & $589.4{ }^{\circ} \mathrm{C}$ \\
Flash point & $324.3{ }^{\circ} \mathrm{C}$ \\
$\log P$ & 7.41 \\
Polar surface area & $44.76 \AA^{2}$ \\
Index of refraction & 1.57 \\
Surface tension & 49.6 dyne cm$^{-1}$
\end{tabular}

in rats are summarized in Table 3. A study by X. Yang et al. showed that HG at an oral dose of $280 \mathrm{mg} \mathrm{kg}^{-1}$ could be detected in rat plasma within $5 \mathrm{~min}$ and reached a peak concentration of $47.73 \pm 1.39 \mathrm{ng} \mathrm{mL}{ }^{-1}$ with a $T_{\max }$ of $18.33 \pm$ $2.58 \mathrm{~min}$, indicating that $\mathrm{HG}$ can be rapidly absorbed in the gastrointestinal tract. Likewise, HG was eliminated quickly with a $t_{1 / 2}$ of $44.06 \pm 2.98 \mathrm{~min}$, a clearance of $128.36 \pm 9.90 \mathrm{~L} \mathrm{~min}^{-1}$ $\mathrm{kg}^{-1}$, and an elimination constant $\left(K_{\mathrm{e}}\right)$ of $0.016 \pm 0.001 \mathrm{~min}^{47}$ In another study, after oral administration of HG at a dose of $232 \mathrm{mg} \mathrm{kg}^{-1}$ in rats, the peak concentration was $30.68 \pm 4.32 \mathrm{ng}$ $\mathrm{mL}^{-1}$ occurring at $21.67 \pm 7.53 \mathrm{~min}$. HG appeared to be eliminated fast with a $t_{1 / 2}$ of $50.87 \pm 21.26 \mathrm{~min}$ and a clearance of $128.36 \pm 9.90 \mathrm{~L} \mathrm{~min}^{-1} \mathrm{~kg}^{-1},{ }^{49}$ which is essentially in agreement with the data reported by X. Yang et al. ${ }^{47}$ In addition, HG could also be detected in the cerebrospinal fluid of rats at a concentration of $6.17 \pm 0.22 \mathrm{ng} \mathrm{mL}{ }^{-1}$ at $20 \mathrm{~min}$, suggesting that it can cross the blood-brain barrier and rapidly distribute into the cerebrospinal fluid. ${ }^{47}$

In some cases, HG has been investigated in vivo as a metabolite of HG-type saponins. E. W. Liu et al. conducted a pharmacokinetic study of $\mathrm{HG}$ as one of the active metabolites of asperosaponin VI (a HG-type saponin), which can be transformed into $\mathrm{HG}$ in vivo resulting in sustained concentrations in the serum. When asperosaponin VI was administrated orally to rats at a dose of $100 \mathrm{mg} \mathrm{kg}^{-1}$, the $C_{\max }$ for HG was determined to be $53.18 \pm 23.27 \mathrm{ng} \mathrm{mL}^{-1}$ with a $T_{\max }$ of $12.33 \pm 2.36 .^{48}$ Similar results were also observed by $\mathrm{H}$. Zhu et al. ${ }^{50}$ In this study, an analytical method for the simultaneous determination of asperosaponin VI and HG in rat plasma was 


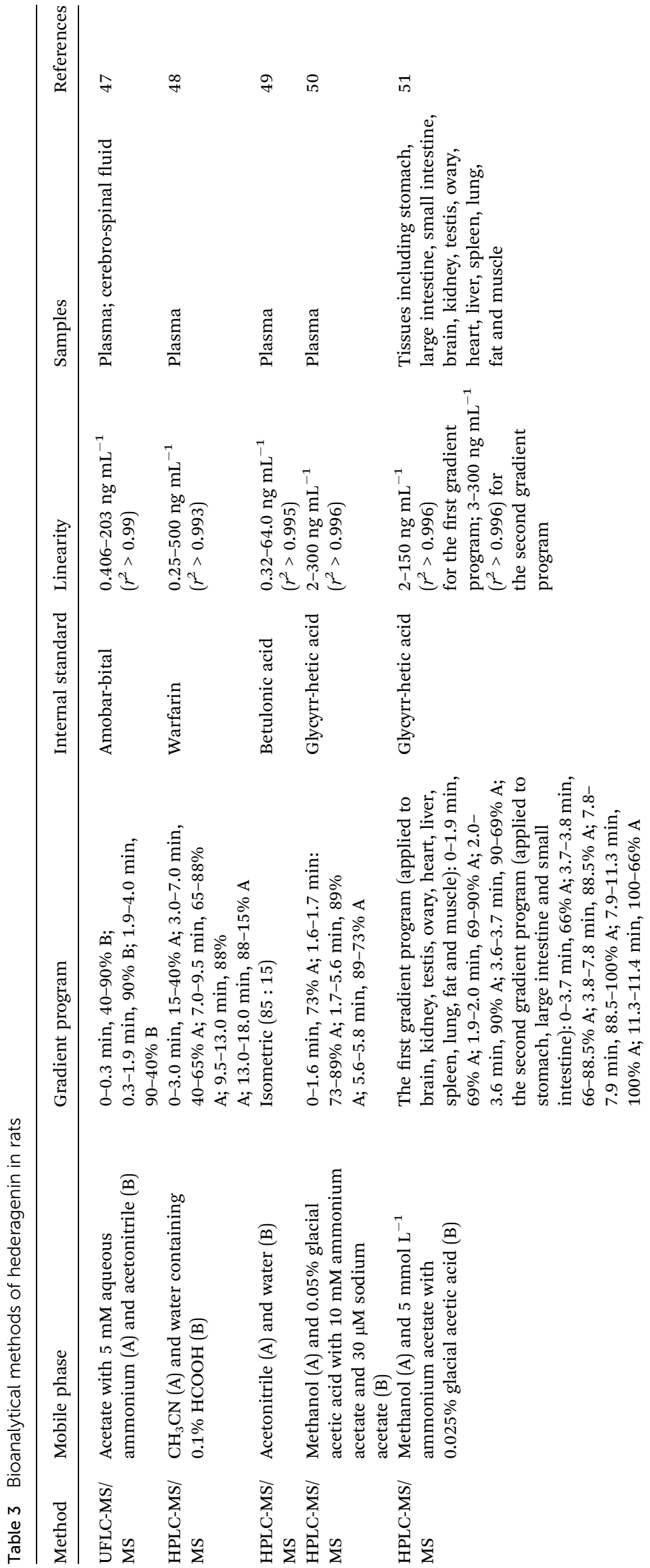


validated. After oral administration of asperosaponin VI at a dose of $90 \mathrm{mg} \mathrm{kg}^{-1}$, HG was first observed at $3 \mathrm{~h}$ with a $C_{\max }$ of $25.5 \pm 11.8 \mathrm{ng} \mathrm{mL}^{-1}$ and a $T_{\max }$ of $13.0 \pm 3.6 \mathrm{~h}$, and the $t_{1 / 2}$ was determined to be $5.6 \pm 3.4 \mathrm{~h}$. Thus, when HG was present as an active metabolite, the elimination time was prolonged by a large extent, which may improve the bioavailability. A tissue distribution study has been performed to determine the concentration of asperosaponin VI and HG in 13 kinds of tissue, including stomach, large intestine, small intestine, brain, kidney, testis, ovary, heart, liver, spleen, lung, fat, and muscle after intragastric administration of asperosaponin VI at a dose of $270 \mathrm{mg}$ $\mathrm{kg}^{-1}$. HG was almost undetectable in most tissues except for the gastrointestinal tract, suggesting that HG was mainly metabolized by intestinal microflora before being absorbed into the plasma. ${ }^{51}$ In general, the known pharmacokinetic properties of HG following oral dosing are a suitable reference for the development and future clinical application of HG.

\section{Pharmacological activities}

\subsection{Anti-tumor activity}

Resistance to chemotherapy is a major obstacle to treating human cancers. The successful development of natural products, such as taxinol and camptothecin, shows the importance of continuing the search for cytotoxic drugs with new mechanisms and unique chemical structures. HG has been shown to have a wide range of potential anti-tumor effects both in vitro and in vivo, which have been evaluated in various types of cancers, including lung, colon, stomach, liver, ovarian, prostate, breast, and endometrial cancers., ${ }^{2,5-23}$ Table 4 summarizes the anti-tumor activity of HG in different tumor cell lines and animal models.

Considerable attention has been devoted to the anti-tumor effect of HG in many tumor cell lines. HG exhibited strong inhibition in 10 human tumor cell lines in vitro (SMM-7721, Bel7402, H08910, PC-3M, A549, HCT-8, CaEs-17, U251, BGC-823, and SGC-7901) with $\mathrm{IC}_{50}$ values of less than $21.16 \mu \mathrm{M} .^{7} \mathrm{HG}$ was also found to be cytotoxic in P-388, L-1210, U-937, HL-60, SNU-5, and HepG2 cell lines with $\mathrm{IC}_{50}$ values in the rage of 8.9-61.0 $\mathrm{MM}^{8}{ }^{8}$ In BALB/c nude mice bearing 9 human cell lines (MCF-7, A549, Hep3B, MGC-803, LoVo, HO-8910PM, HEC-1, K562, and Eca-109) as tumor models, HG at a dose of 45$405 \mathrm{mg} \mathrm{kg}^{-1}$ showed anti-tumor activity with tumor inhibition rates of more than $60 \%{ }^{9}$

The anti-tumor mechanisms of HG toward some tumors have been elucidated at the molecular level by gene or protein expression. In a study of the anti-hepatoma effect, HG decreased the tumor weight in $\mathrm{H}_{22}$ tumor-bearing mice, and increased the expression of P21, Bax, Fas, Fasl, caspase-3, and caspase- 8 genes; Bax, Fas, Fasl, caspase-3, and caspase-8 mRNA; and Bax, Fasl, caspase- 3 , and caspase- 8 proteins, whereas HG decreased the expression of mutant P53 and Bcl-2 genes; and Bcl-2 mRNA and Bcl-2 proteins. ${ }^{10,11}$ In a study of the antiprostate cancer effect of HG, HG dose-dependently (52.89$211.55 \mu \mathrm{M}$ ) inhibited the proliferation, migration, and invasion of DU145 cells, as well as promoting cell apoptosis. HG decreased the relative expression levels of Bcl-2, PI3K, and Akt
mRNA and proteins, and increased the relative expression levels of Bax mRNA and proteins. Thus, the mechanism of action might be related to inhibition of the PI3K/Akt signaling pathway. ${ }^{12}$ In a study of the anti-leukemic effect, HG inhibited the proliferation of HL-60 at concentrations of $10-40 \mu \mathrm{M}$, and caused cell death at concentrations of $40-50 \mu \mathrm{M}$. The mechanism for this is likely to involve G1 phase arrest and apoptosis. ${ }^{13}$ In non-small cell lung cancer and breast cancer cell lines, HG exhibited cytotoxicity against A549 and BT20 cells with death rates of $99.1 \%$ and $99.7 \%$, respectively, and $\mathrm{IC}_{50}$ values of 26.3 and $11.8 \mu \mathrm{M}$, respectively. This cytotoxic activity may be related to inducing apoptosis, increasing the cell membrane permeability, reducing the mitochondrial potential, and suppressing NF- $\kappa \mathrm{B}$ activation. ${ }^{6}$ In head and neck cancer cell lines, HG selectively induced cell death in HNC cells by promoting changes in mitochondrial membrane potential and inducing apoptosis. HG inhibited the Nrf2-antioxidant response element pathway and activated p53 in HNC cells, thereby enhancing reactive oxygen species production and promoting glutathione depletion. This effect was also confirmed in mouse tumor xenograft models. The mechanism was related to activating intrinsic apoptotic pathways via cleaved poly ADP-ribose polymerase, cleaved caspase-3, and Bax. ${ }^{\mathbf{1 4}}$

In addition, investigation of the anti-colon cancer effect of HG has attracted special attention. In a study by Y. Chen, ${ }^{5}$ HG suppressed epithelial-mesenchymal transition and invasion of the colon cancer cells SW480 in a dose- and time-dependent manner. HG reduced the expression of the epithelial-mesenchymal transition markers $\mathrm{N}$-cadherin, vimentin, and snail, as well as the invasion and metastasis markers STAT-3, MMP-9, and MMP-14, and enhanced the expression of E-cadherin and RECK. A study by B. X. Liu ${ }^{15}$ showed that HG inhibited the viability of the colon cancer cells LoVo in a dose- and timedependent manner with an $\mathrm{IC}_{50}$ value of $1.17 \mu \mathrm{M}$. $\mathrm{HG}$ also induced nuclear changes characteristic of apoptosis and increased the levels of reactive oxygen species in LoVo cells. Furthermore, HG up-regulated Bax, caspase-3, and caspase-9, and down-regulated MMP, Bcl-2, Bcl-xL, survivin, procaspase9, procaspase-3, and poly (ADP-ribose) polymerase in LoVo cells. Another study investigated the effect of HG in combination with 5-fluorouracil oxaliplatin on the human colon adenocarcinoma cell line HT-29, in which HG had an inhibitory effect on the proliferation of HT-29 with enhanced efficacy. One possible mechanism is the down-regulation of HT-29 in TSmRNA and ERCC1 mRNA; down-regulation of BRCA1 mRNA expression; and up-regulation of OPRT mRNA expression. ${ }^{\mathbf{1 6}}$ These studies indicated that HG has effective anti-tumor activity and could play an important role in cancer treatment.

Structural modification of triterpenoids has been demonstrated to enhance their pharmacological activities. ${ }^{86-88}$ Studies have provided more insight into the potential of $\mathrm{HG}$ as a viable anti-tumor drug candidate based on the exploration and screening of derivatives with structural modifications. A series of 60 different esters, amides, and triazolyl derivatives of $\mathrm{HG}$ at the C-28 position were synthesized and their cytotoxic activities were tested on 6 human cancer cell lines (518A2, A2780, HT29, MCF7, A549, and 8505C). In general, the conversion of HG into 


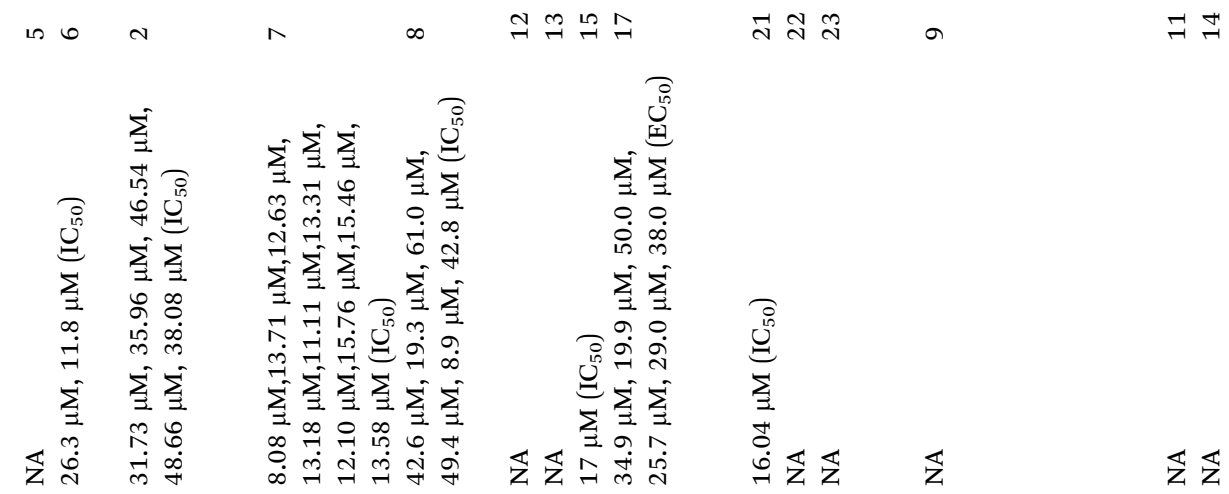

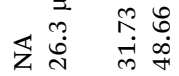

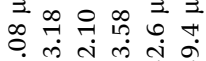

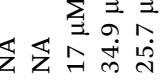

它艺艺艺

飞艺

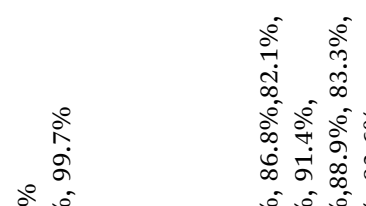

文

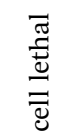

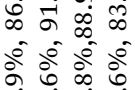

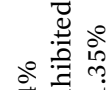

空

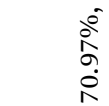

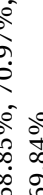

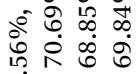

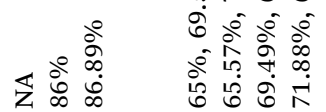

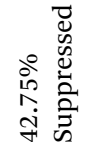
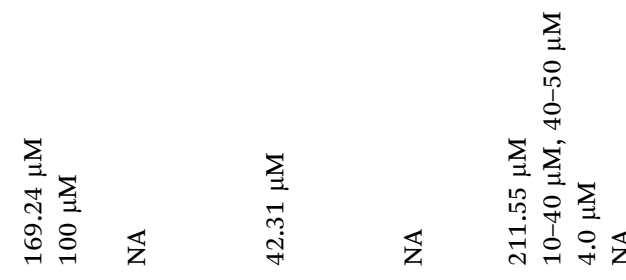

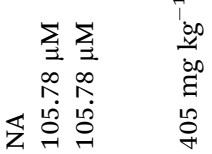

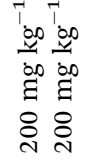

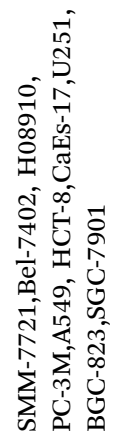

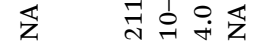

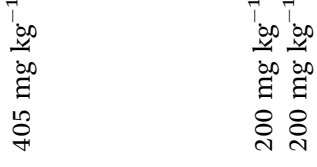

党要

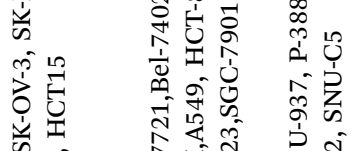

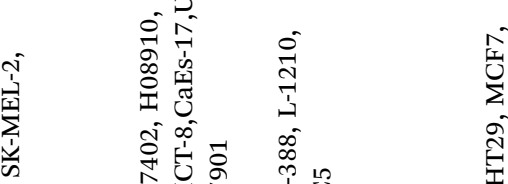

全

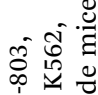

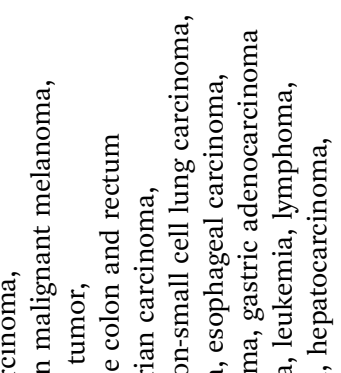

ô

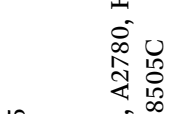

ব্

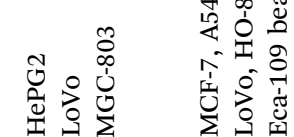
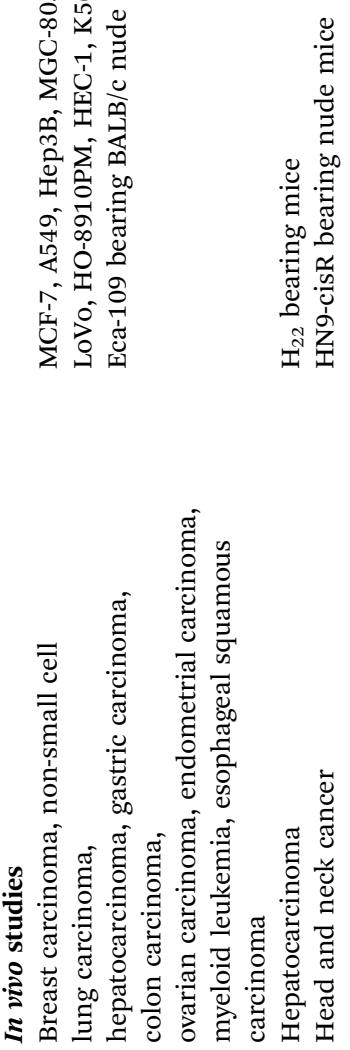
derivatives resulted in an increase in cytotoxicity, with some exceptions. Compounds 1 and 2 (Fig. 3) carrying benzyl and ortho-nitrobenzyl groups, respectively, were the most active of the esters with $\mathrm{EC}_{50}$ values in the range of 6.1-9.7 $\mu \mathrm{M}$ for all cell lines, and were approximately 20 times more cytotoxic than HG itself. Compounds 3 and 4 (Fig. 3) carrying ethyl piperidine and ethyl pyrrolidinyl substituents, respectively, were the most active of the amides with $\mathrm{EC}_{50}$ values in the range of 1.1-6.5 $\mu \mathrm{M}$ for all cell lines and were approximately 30 times more potent than HG. Compound $\mathbf{4}$ was shown to exert its anti-tumor activity via apoptosis in an $\mathrm{AO} / \mathrm{P}$ staining experiment. Compounds 5-7 (Fig. 3) possessing $m$-bromo, $m$-chloro, and $m$-nitro substituents, respectively, were the most active of the triazolyls with $\mathrm{EC}_{50}$ values in the range of 3.0-4.1 $\mu \mathrm{M}$ toward all cell lines, and were at least 8 times more active than $\mathrm{HG}^{\mathbf{1 7 , 1 8}}$ In another study by the same investigator, HG was converted into several 1,2,3triazolyl derivatives at both the $\mathrm{C}-23$ and $\mathrm{C}-28$ positions. Compound 8 (Fig. 3) carrying a substituted 2-( $p$-cyanophenyl)-2oxoethyl group was the most cytotoxic against FaDu, A2780, $\mathrm{HT} 29, \mathrm{~A} 375$, and SW1736 cell lines with $\mathrm{EC}_{50}$ values in the range of 7.4-12.1 $\mu \mathrm{M}$, and had higher cytotoxic activity compared with $\mathrm{HG}\left(\mathrm{EC}_{50}>60 \mu \mathrm{M}\right)$ and the standard compound, betulinic acid $\left(\mathrm{EC}_{50}: 12.0-18.4 \mu \mathrm{M}\right)$. This activity was likely the result of cytostatic effects because inhibition of cell growth was observed. The addition of a triazolyl core at the C-23 position had no influence on the cytotoxicity of this class of compounds. ${ }^{19} \mathrm{~A}$ recent report has shown that a HG derivative possessing three nitrogen atoms (as a polyamine) at the C-23 position exhibited

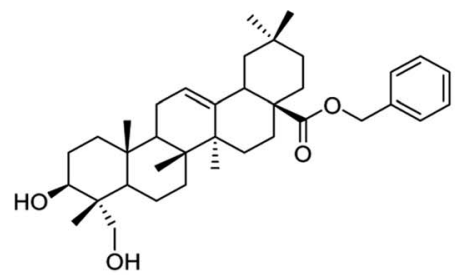

1

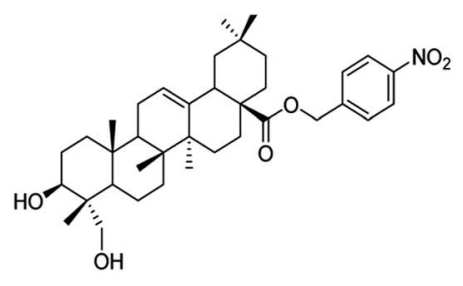

2

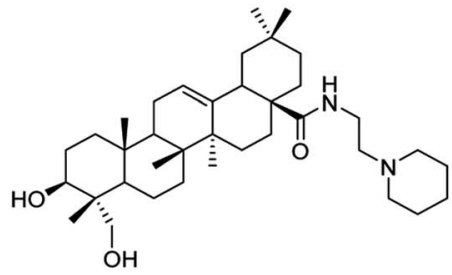

3

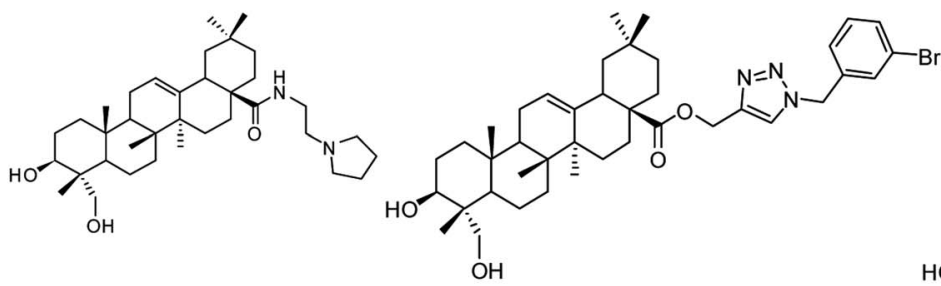

4

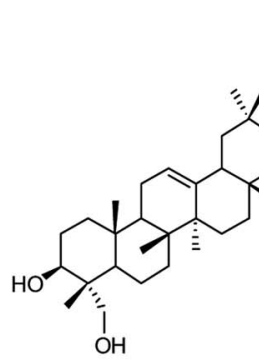

5 $\mathrm{H}$<smiles>CC1(C)CC[C@]2(C(=O)OCc3cn(Cc4cccc(Cl)c4)nn3)CC[C@]3(C)C(=CC[C@@H]4[C@@]5(C)CC[C@H](O)[C@](C)(CO)C5CC[C@]43C)C2C1</smiles>
6

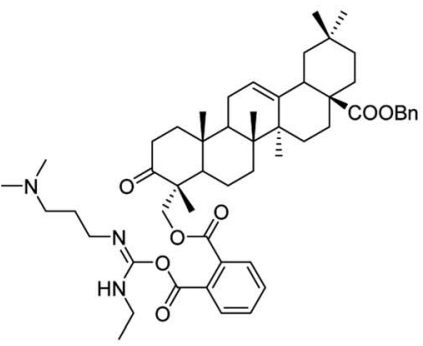

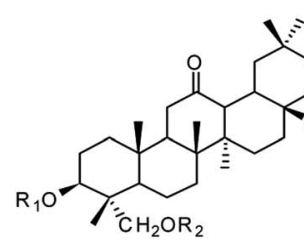

7
8

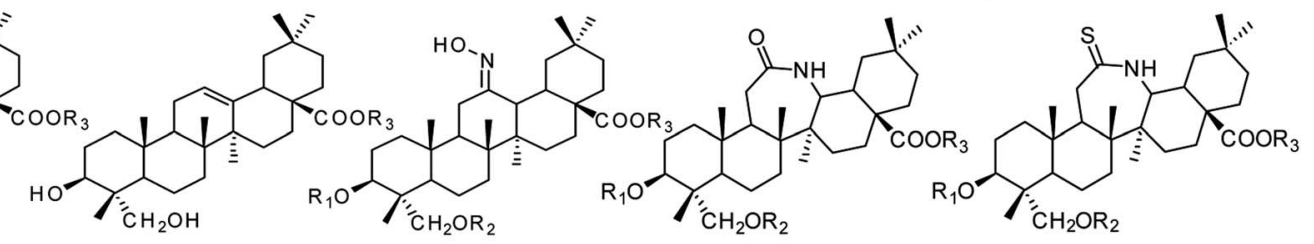

9

$\mathrm{R}_{1}$ : - $\mathrm{COCH}_{3},-\mathrm{COCH}_{2} \mathrm{CH}_{3},-\mathrm{COCH}_{2} \mathrm{CH}_{2} \mathrm{CH}_{3},-\mathrm{COCH}_{2} \mathrm{CH}_{2} \mathrm{CH}_{2} \mathrm{CH}_{3}$ $\mathrm{R}_{2}$ : - $\mathrm{COCH}_{3},-\mathrm{COCH}_{2} \mathrm{CH}_{3},-\mathrm{COCH}_{2} \mathrm{CH}_{2} \mathrm{CH}_{3},-\mathrm{COCH}_{2} \mathrm{CH}_{2} \mathrm{CH}_{2} \mathrm{CH}_{3}$ $\mathrm{R}_{3}$ : - $\mathrm{CH}_{3},-\mathrm{CH}_{2} \mathrm{CH}_{3},-\mathrm{CH}_{2} \mathrm{CH}_{2} \mathrm{CH}_{3},-\mathrm{CH}_{2} \mathrm{CH}_{2} \mathrm{CH}_{2} \mathrm{CH}_{3}$

Fig. 3 Derivatives of hederagenin related to anti-tumor activity. 
more potent antitumor activity than compounds with zero to two nitrogen atoms. ${ }^{20}$ In this study, 24 derivatives were synthesized and screened for in vitro cytotoxicity against $\mathrm{KB}$, KBV, Hela, A549, MKN45, BGC-823, and AGS cell lines. Compound 9 (Fig. 3) displayed anti-proliferative activity in all the cell lines with $\mathrm{IC}_{50}$ values in the range of $4.22-8.05 \mu \mathrm{M}$, which was at least 8 times higher than HG. This compound induced apoptosis in MKN45 cells as indicated by the ratio of cells in the sub-G0/G1 phase and increased the abundance of cleaved poly-ADP ribose polymerase. In addition, this derivative decreased the expression of BCL2 protein, increased the expression of BAX protein, and elevated the ratio of $\mathrm{Bax} / \mathrm{Bcl}-2$, suggesting that it triggered apoptosis via an intrinsic mitochondrial pathway. ${ }^{20} 6$ derivatives of $\mathrm{HG}$ modified at the $\mathrm{C}-3, \mathrm{C}-$ 12, C-13, C-23, and C-28 positions were also synthesized, and their anti-hepatoma effects were evaluated in HepG2 cells in an in vitro model. Compounds 10-14 (Fig. 3) showed more potent activity compared with $\mathrm{HG}$ with lower $\mathrm{IC}_{50}$ values. ${ }^{21}$ These findings indicated that the presence of a bulky group on the triterpene skeleton may modulate the cytotoxic activity of HG derivatives.

\subsection{Anti-inflammatory activity}

Triterpenoids isolated from diverse plant families are known to possess anti-inflammatory activity. As early as in the 1970s, HG was found to show anti-inflammatory and anti-arthritic activities in rats. ${ }^{28}$ In a mouse-ear edema model, where edema was induced by either croton-oil or arachidonic acid, HG at a dose of $100 \mathrm{mg} \mathrm{kg}{ }^{-1}$ showed anti-inflammatory activity with inhibition of $42 \%$ and $23 \%$, respectively. ${ }^{29,30}$ In another rat model of carrageenan-induced edema, HG at doses of 100 and $200 \mathrm{mg}$ $\mathrm{kg}^{-1}$ via intraperitoneal administration caused inhibition of $36 \%$ and $44 \%$, respectively, and produced a slight inhibition of granuloma and exudate formation in rats at the same dose via oral administration. HG at a dose of $50-200 \mathrm{mg} \mathrm{kg}^{-1}$ orally showed a dose-dependent tendency to inhibit the development of edema in the rat hind paw. ${ }^{27}$ In lipopolysaccharidestimulated RAW 264.7 cells, HG inhibited the levels of protein expression of iNOS, COX-2, and NF- $\kappa \mathrm{B}$, as well as the production of NO, $\mathrm{PGE}_{2}$, TNF- $\alpha$, IL-1 $\beta$, and IL- 6 at concentrations of 10,30 , and $100 \mu \mathrm{M}$. HG also dose-dependently reduced the mRNA levels of iNOS and COX-2, and the above-mentioned cytokines. Furthermore, at a dose of $30 \mathrm{mg} \mathrm{kg}^{-1}$, HG inhibited the carrageenan-induced increases in skin thicknesses, infiltrated inflammatory cells, and induced mast cell degranulation. ${ }^{26}$ Recent research has shown that HG has the potential to scavenge free radicals and suppress the generation of NO attributable to inhibition of the de novo synthesis and catalytic activity of iNOS in inflammatory leukocytes, including neutrophils and macrophages with an $\mathrm{IC}_{50}$ value of $52.89 \mu \mathrm{M}$. In addition, HG alleviated ethanol-induced liver injury and inflammation by decreasing serum TNF- $\alpha$ and IL-6 levels, and reduced the inflammatory response to ethanol by suppressing levels of hepatic TNF- $\alpha$, IL-6, and COX-2 mRNA expression. ${ }^{25}$ The complement system is a major effector of humoral immunity involved in host defense. Thus, modulation of complement activity is useful in therapies for inflammatory diseases. HG exhibited potent anti-complementary activity in vitro on the classical pathway of the complement system with an $\mathrm{IC}_{50}$ value of $160 \mu \mathrm{M}$, and its carboxylic group was shown to be an essential feature for this activity. ${ }^{24}$

\subsection{Anti-depressant activity}

Previous studies have demonstrated that HG has an antidepressant effect by enhancing the signaling of central monoamines via inhibition of the reuptake of extracellular monoamines, including serotonin (5-HT), norepinephrine (NE), and dopamine (DA). ${ }^{32,33}$ In ex vivo and in vitro experiments, HG displayed affinity toward rat and cloned human monoamine transporters. However, HG showed no affinity toward a variety of other receptors from the central nervous system. In uptake assays using rat synaptosomes and transfected cells, HG was found to inhibit 5-HT, NE, and DA in a dose- and timedependent manner, with a potency comparable to, or stronger than their corresponding specific inhibitors. Moreover, HG increased the extracellular concentrations of 5-HT, NE, and DA in the frontal cortexes of freely moving rats. Thus, HG was shown to be a new triple inhibitor of monoamine transporters. ${ }^{31}$ In a behavioral despair test and unpredictable chronic mild stress rat model, HG increased NE and 5-HT levels and showed a tendency to increase the expression of 5 -HT $1 \mathrm{~A}$ receptor mRNA, and decreased expression of the mRNA of the serotonin transporter (5-HTT). ${ }^{34}$

A derivative of HG was designed and synthesized by structural modification at the $\mathrm{C}-28$ position to investigate the antidepressant activity. Compound $\mathbf{1 5}$ (Fig. 4) showed a protective effect on injuries induced by corticosterone in primary cultured hippocampal neurons at a concentration of $0.1 \mu \mathrm{M}$. This compound also decreased the duration of immobility in the tail suspension test by acute delivery and promoted the expression of brain-derived neurotrophic factor and synaptophysin. ${ }^{35}$

\subsection{Anti-neurodegenerative activity}

Some specific triterpenoid saponins isolated from herbal plants have been shown to be novel autophagic inducers that facilitate autophagic degradation and alleviate the toxicity of neurodegenerative disease proteins. ${ }^{89}$ HG-activated autophagy via the AMPK-mTOR and autophagy-related gene 7 (ATG 7) signaling pathways was able to accelerate the clearance of mutant huntingtin with 74 CAG repeats and A53T $\alpha$-synuclein and inhibit the oligomerization of $\alpha$-synuclein in cellular models. A

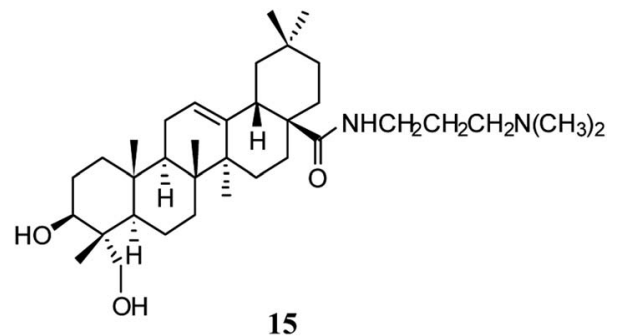

Fig. 4 Derivative of hederagenin related to anti-depressant activity. 
potential neuro-protective effect for HG in modulating Parkinson's and Huntington's diseases has been proposed based on its ability to facilitate the degradation of neurodegenerative disease proteins in cellular models, and to improve the motor deficit of neurotoxin injected mice. ${ }^{36} \mathrm{HG}$ at concentrations of 3.13 and $6.25 \mu \mathrm{M}$ was found to have a repairing action in the PC 12 cell injury model induced by A $325-35$. A high dose of $270 \mathrm{mg}$ $\mathrm{kg}^{-1}$ improved the learning and memory ability of mice after cholinergic system damage induced by scopolamine, and increased cerebral superoxide dismutase (SOD) activity and reduced TchE levels, which indicated that HG has potential for the treatment of senile dementia and brain nerve injury. ${ }^{37}$

Compound 16 (Fig. 5) was obtained by esterification of the C3, C23-hydroxyl and condensation of the C28-carboxyl of HG. At a dosage of $7.5,15$, and $30 \mathrm{mg} \mathrm{kg}^{-1}$, this compound prevented memory impairment in mice induced by aluminum muriate, scopolamine hydrobromide, or $30 \%$ ethanol aqueous solution by varying degrees, and reduced the number and the incidence of errors in the mice. In addition, this compound increased cerebral SOD activity and the cerebral coefficient but decreased the content of cerebral malondialdehyde and acetylcholine in an Alzheimer's disease model. Thus, compound 16 had a preventive and therapeutic effect on Alzheimer's disease, which was greater than that of HG. ${ }^{38}$

\subsection{Anti-hyperlipidemia activity}

Hyperlipidemia has been recognized as the leading cause of atherosclerosis and cardiovascular and cerebrovascular diseases by the world medical community. Good control of blood lipids can reduce the morbidity and mortality associated with atherosclerosis-related cardiovascular and cerebrovascular diseases. ${ }^{90} \mathrm{HG}$ at a dose of $500 \mathrm{mg} \mathrm{kg}{ }^{-1}$ reduced the serum cholesterol levels in experimental hyperlipidemia mice, which was a more potent effect than that of nicotinic acid tablets at a dose of $600 \mathrm{mg} \mathrm{kg}^{-1}$. HG at a dose of $100 \mathrm{mg} \mathrm{kg}^{-1}$ reduced serum total cholesterol (TC) levels and improved hemorheological properties in experimental hyperlipidemia rats by reducing the whole blood viscosity at high, medium, and low shear rates, as well as plasma viscosity at a dose of $200 \mathrm{mg} \mathrm{kg}^{-1}$, which was comparable to that of nicotinic acid tablets at a dose of $300 \mathrm{mg} \mathrm{kg}^{-1}$ and Di'ao capsules at a dose of $400 \mathrm{mg} \mathrm{kg}^{-1} \cdot{ }^{39} \mathrm{In}$ another study, $\mathrm{HG}$ at doses of 50 and $150 \mathrm{mg} \mathrm{kg}^{-1}$ reduced the $\mathrm{TC}$, triglyceride (TG), and low density lipoprotein cholesterol

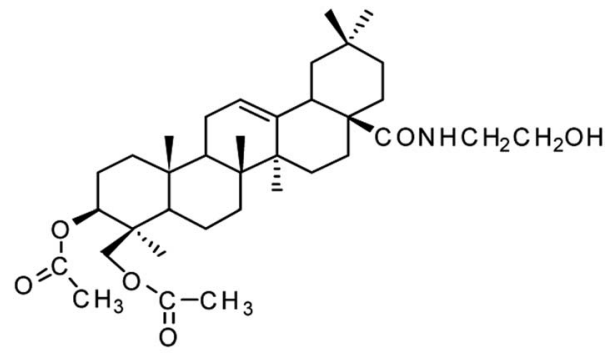

16

Fig. 5 Derivative of hederagenin related to anti-neurodegenerative activity.
(LDL-C) levels in hyperlipidemic rats, and increased the high density lipoprotein cholesterol (HDL-C) levels at a dose of $150 \mathrm{mg} \mathrm{kg}^{-1}$, which was similar to the effect of oral capsules of Xuezhikang. ${ }^{40}$ In a Wistar rat atherosclerosis model, HG at a dose of $20 \mathrm{mg} \mathrm{kg}^{-1}$ reduced TC, TG, LDL-C, ALT, and AST levels and hemorheological parameters, and increased HDL-C levels and the high shear whole-blood viscosity index. The mechanism of action of HG may be related to the regulation of lipid metabolism, protection of liver function, improvement of blood rheology, and regulation of endothelial dysfunction. ${ }^{4}$

\subsection{Anti-diabetic activity}

The development of type-2 diabetes is thought to be the result of a combination of genetic and environmental factors. There is evidence that a disorder in insulin signal transduction plays a critical role in the pathogenesis of type- 2 diabetes. ${ }^{4}$ Protein tyrosine phosphatase 1B is a key negative regulator of insulin signaling. HG was able to inhibit protein tyrosine phosphatase 1B with an $\mathrm{IC}_{50}$ value of $70 \mu \mathrm{M}$, and increase AKT phosphorylation of CHO cells, at a concentration of $105.78 \mu \mathrm{M}$. A possible mechanism may be related to the stimulus and transport of GLUT4 via the PI3K/AKT pathway. ${ }^{43}$ Glycogen phosphorylase (GP) is the enzyme mainly responsible for the modulation of glycogen metabolism, so pharmacological inhibition of GP is regarded as a promising therapeutic approach for treating diseases caused by abnormalities in glycogen metabolism, such as diabetes. HG inhibited GP with an inhibition rate of $73.07 \%$ at a concentration of $10 \mu \mathrm{M} .^{42}$ Furthermore, in a streptozotocin-induced diabetic rat model, HG at a dose of $50 \mathrm{mg} \mathrm{kg}^{-1}$ reduced the serum glucose levels of diabetic rats by $37.15 \%$, showing a mild anti-diabetic action. ${ }^{41}$

\subsection{Anti-leishmanial activity}

HG is commonly used as a biopesticide. The leishmanicidal activity of the HG sodium salt was estimated in vitro on the promastigote and amastigote forms of two strains of Leishmania infantum isolated from dogs and a strain of Leishmania tropica isolated from man. HG exhibited activity against the promastigote forms at concentrations of 50.54-202.14 $\mu \mathrm{M}$, and activity against the amastigote forms was equivalent to that of the reference compound, $\mathrm{N}$-methylglucamine antimonate. ${ }^{44}$

Furthermore, to develop agents with higher activity, 60 derivatives of HG (esters, amides, 1,2,3-triazolyl esters, and 1,2,3-triazolyl amides) were synthesized, carrying different groups at the C-28 position, and 19 bis-triazolyl derivatives of HG were synthesized by modifying the C-23 and C-28 positions simultaneously. The in vitro anti-leishmanial activity was evaluated in the intracellular amastigote form of L. infantum (BH46) parasitized macrophages (DH82). 11 derivatives modified at the C-28 position and 7 derivatives simultaneously modified at the C-23 and C-28 positions reduced the multiplication of amastigotes of $L$. infantum by at least $50 \%$. In general, the most active compounds bore a substituent at the para or ortho positions. Compounds 17-24 (Fig. 6) exhibited qualified selectivity indexes ${ }^{91,92}$ for potential drug candidates that were more active than HG. These active compounds prevented the proliferation of intracellular amastigote forms of $L$. infantum with $\mathrm{IC}_{50}$ values 
<smiles>CC1(C)CC[C@]2(C(=O)Oc3cccc([N+](=O)[O-])c3)CC[C@]3(C)C(=CCC4[C@@]5(C)CC[C@H](O)[C@@](C)(CO)C5CC[C@]43C)C2C1</smiles>

17

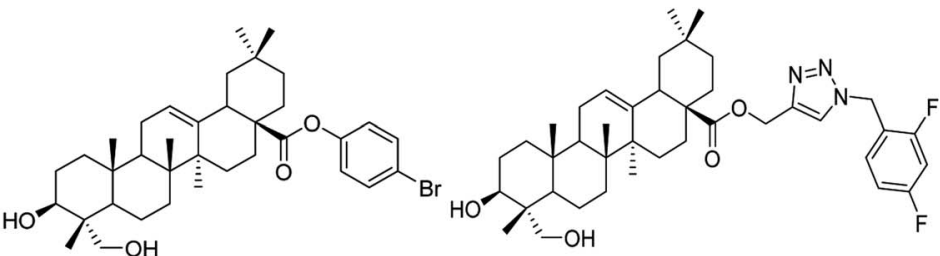

18

19

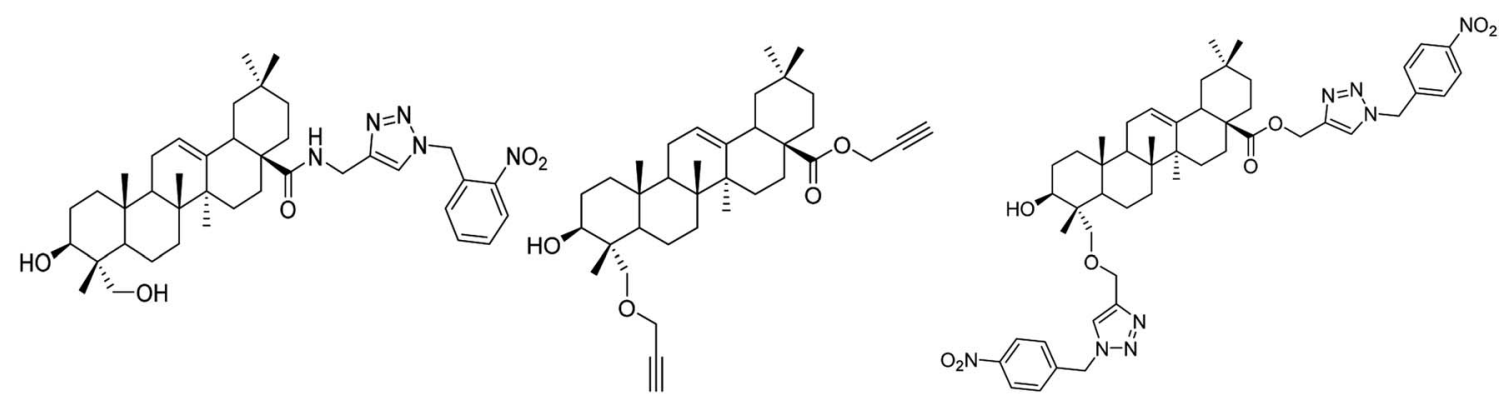

20

21

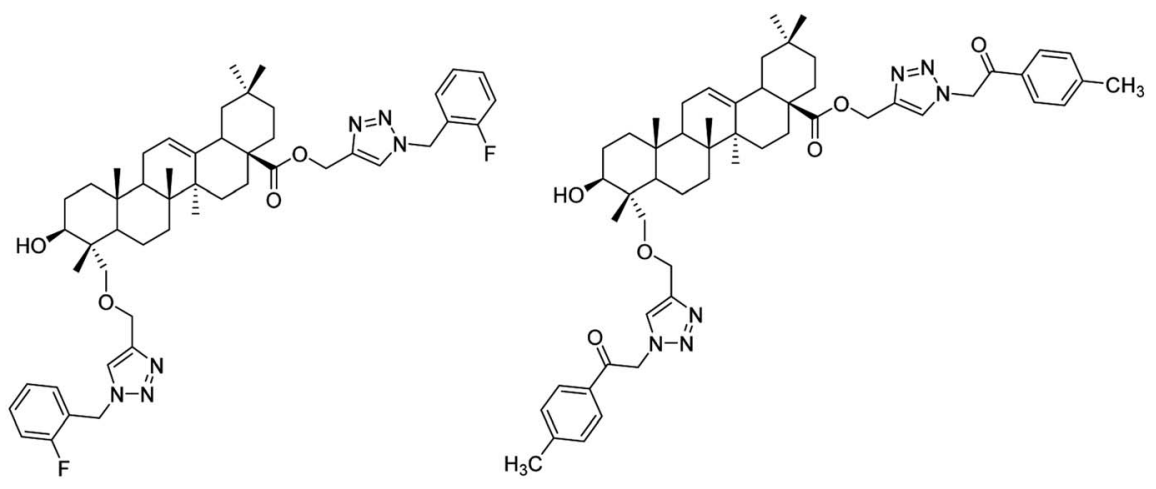

23

Fig. 6 Derivatives of hederagenin related to anti-leishmanial activity.

in the range of $2-28.8 \mu \mathrm{M}$. In particular, the derivatives substituted with an $o$-fluorobenzyl or a 2 -( $p$-methylphenyl)-2oxoethyl moiety linked to a 1,2,3-triazolyl group were the most potent, with an activity 11- and 8-fold higher than HG, respectively. Moreover, the investigator found that by adding a triazolyl core at the C-23 position, the toxicity toward the $L$. infantum parasite was approximately the same as for $\mathrm{HG}$, but with improved selectivity. The mechanism of action for HG and compounds 22-24 may be related to interactions in the binding site of the enzyme CYP51 $1_{\mathrm{Li}}$, which is involved in the survival and virulence of Trypanosoma and Leishmania species. ${ }^{19,45}$ These encouraging findings showed that structural modifications at the $\mathrm{C}-28$ position, and C-23 and C-28 positions simultaneously, can result in improvements in bioactivity, which indicates that derivatives of HG are potential candidates for the treatment of leishmaniasis.

\subsection{Anti-viral activity against the hepatitis $B$ virus}

Compounds 25-32 (Fig. 7) were synthesized by acetylation, etherification, benzoylation, and esterification at the C-3, C-23, and $\mathrm{C}-28$ positions of $\mathrm{HG}$, and the anti-viral activity against the hepatitis B virus was determined in Hep G2.2.15 cells. These compounds inhibited cell viability in a concentrationdependent manner, especially compounds $\mathbf{3 0}$ and 32, which showed an inhibitory effect on the secretory expression of HbsAg. ${ }^{46}$

\section{Safety}

No human fatality from HG has been reported to date in the scientific literature. No toxic effects nor death have been observed in the mouse acute general toxicity test, and the maximum tolerated dose of HG was higher than $20 \mathrm{~g} \mathrm{~kg}^{-1}$ when orally administered. ${ }^{39}$ The $\mathrm{LD}_{50}$ value of $\mathrm{HG}$ in mice was determined to be $600 \mathrm{mg} \mathrm{kg}{ }^{-1}$ via intraperitoneal administration, ${ }^{93}$ without obvious toxicity or side effects observed in the liver and kidney. ${ }^{\mathbf{1 0}}$ Moreover, HG was able to exert its biological functions at concentrations that caused no obvious cytotoxicity toward normal cells. ${ }^{36}$ However, there is evidence showing that HG may be potentially toxic to animal species other than rats 


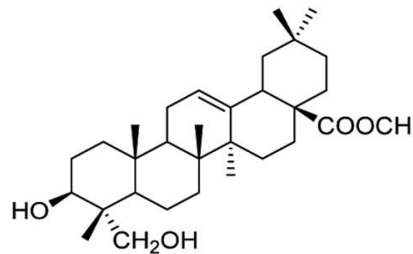

25

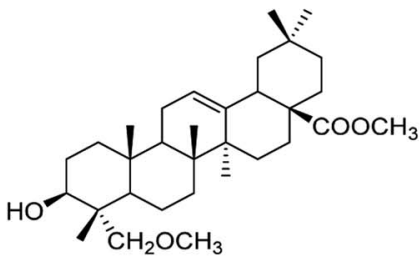

29

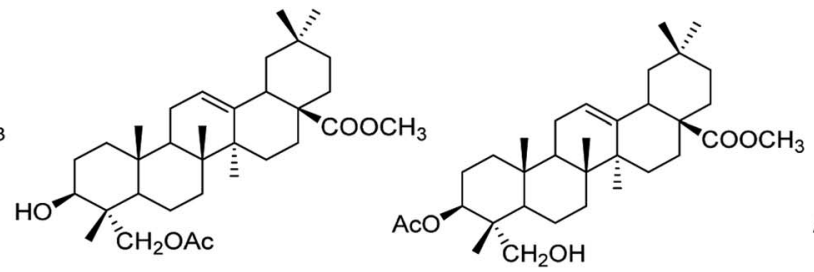

27

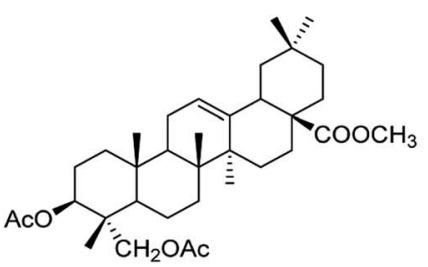

28

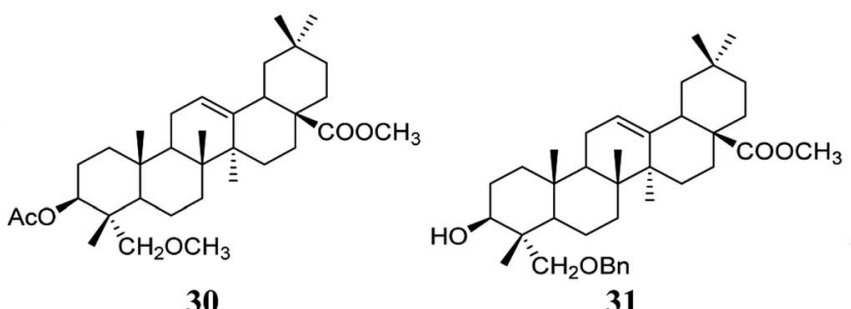

30

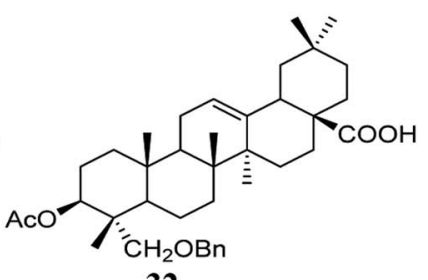

32

Fig. 7 Derivatives of hederagenin related to anti-hepatitis B virus activity.

and mice. The deaths of two cows and one dog were registered in France between 1990-1992 indicating the potential toxicity of the English ivy plant from which HG is derived. ${ }^{94}$ Furthermore, some authorities including the United States Department of Agriculture, the American Society for the Prevention of Cruelty to Animals, and the Animal Emergency Centre have also reported that this plant was toxic to dogs, cats, goats, and horses. The typical symptoms included excessive salivation, nausea, excitement, difficulty in breathing, severe diarrhea, thirst, and coma. ${ }^{95-97}$ The concentrations of three potential toxic compounds, hederacoside $\mathrm{C}, \boldsymbol{\alpha}$-hederine (both glycosides of HG), and HG, in the powdered dried leaves of English ivy were determined to be $21.83,0.41$, and $0.02 \mathrm{mg} \mathrm{g}^{-1}$, respectively, which indicated that hederacoside $\mathrm{C}$ was the main toxin present, being 50 and 1000 times more concentrated than $\alpha$ hederin and $\mathrm{HG}$, respectively. ${ }^{98}$

In addition, it is well known that the erythrocyte hemolysisinduced toxicity in most animals, including humans, is a great challenge for the clinical development of the majority of saponins or sapogenins as pharmaceutical agents, especially when administrated by injection. Compounds of this type produce large amounts of foam when mixed with water, and their amphiphilic properties enable them to interact with erythrocyte membranes as surfactants and thus disrupt the membrane..$^{99,100}$ The skeleton type, distribution of functional groups, stereochemical configuration of substituents at different positions of the aglycone, as well as the complexity of the sugar moieties are all important factors that affect the hemolytic activity. Accordingly, some saponins exhibit a strong hemolytic activity, while others exhibit only weak or no hemolytic effects. HG showed moderate intrinsic hemolytic activity with an $\mathrm{HD}_{100}$ value $(100 \%$ hemolytic dose) of approximately $2000 \mu \mathrm{g} \mathrm{mL}{ }^{-1} \cdot{ }^{101}$ A possible reason for the hemolytic activity of HG is that it may permeabilize the erythrocyte membrane. ${ }^{102}$ Structure and activity relationship studies on the hemolytic activity have suggested that a polar group at the C-28 position (carboxyl) is a structural element of oleanane-type saponins that considerably enhances hemolysis, while the absence of this function, glucosylation at the C-28 position, or the presence of a methyl hydroxyl at the C23 position is closely associated with a reduction in hemolytic activity. ${ }^{101}$ Findings from the relationships between the structure and the hemolytic activity have contributed to the design and synthesis of derivatives of HG that are non-toxic or less toxic to erythrocytes.

\section{Challenges and future perspectives}

HG and its glycosides can be obtained in large quantities from natural sources, and these compounds have attracted increasing attention in recent years for their potential use as pharmaceuticals. In summary, HG is a promising natural bioactive substance with a variety of pharmacological activities for the potential treatment of many diseases. Great progress has been achieved in the investigation of its pharmacological activities and mechanisms of action (Fig. 8). HG consists of a 30carbon skeleton with five available sites at the C-3, C-12, C-13, C23, and C-28 positions for chemical modifications, which enables the synthesis of novel compounds with potentially higher potency and selectivity, and with fewer side effects.

Despite extensive research and development into HG in recent years, considerable challenges still lie ahead because of the limitations in its physicochemical properties and pharmacokinetic and safety profiles, as well the limited amount of research on the pharmacological activity and mechanisms of action to date. HG has relatively low bioavailability because it has poor water solubility, and it has a very short half-life after oral absorption. Consequently, the dosing of HG must be frequent, resulting in fluctuations in the plasma drug concentration and increasing the risk of a poor clinical outcome, including side effects and adverse reactions, limiting the application of HG in clinical use. Considering that triterpenes are known to possess a wide range of pharmacological activities, it is possible that other new pharmacological effects of HG still 

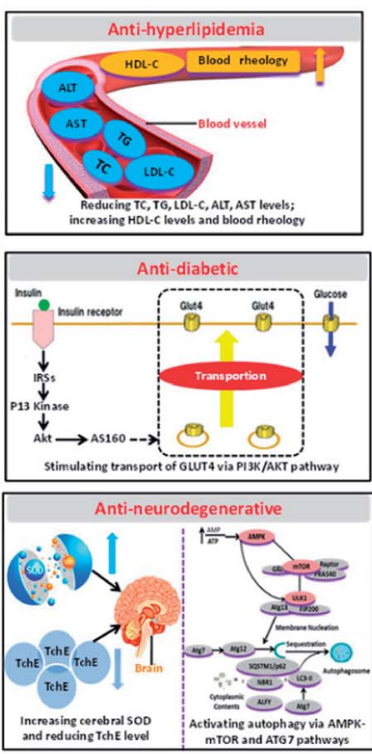
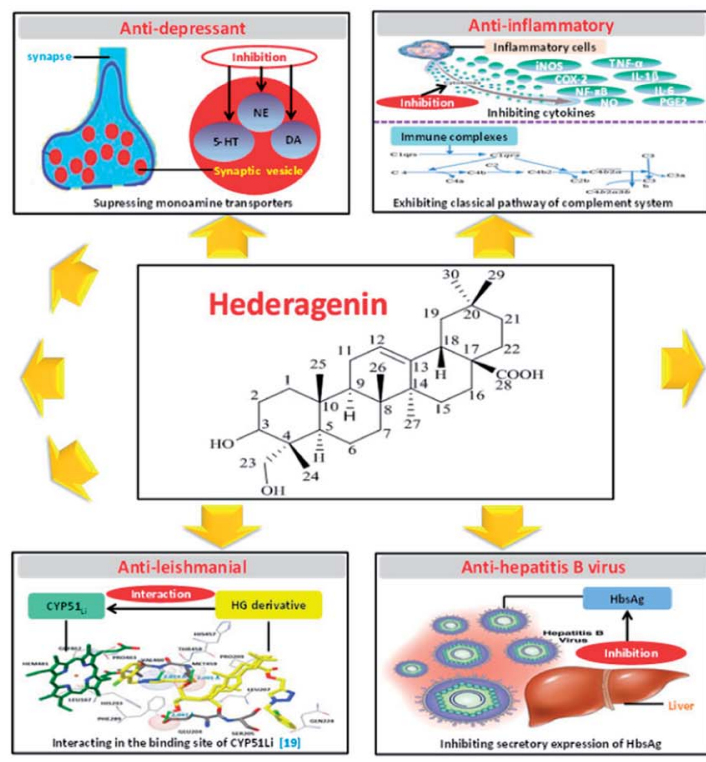
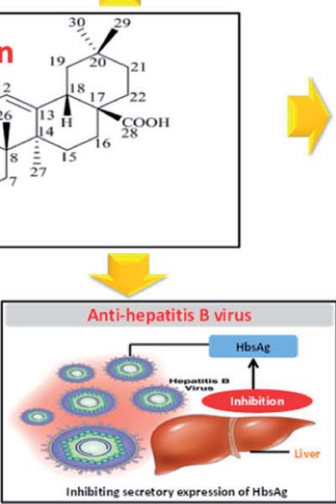

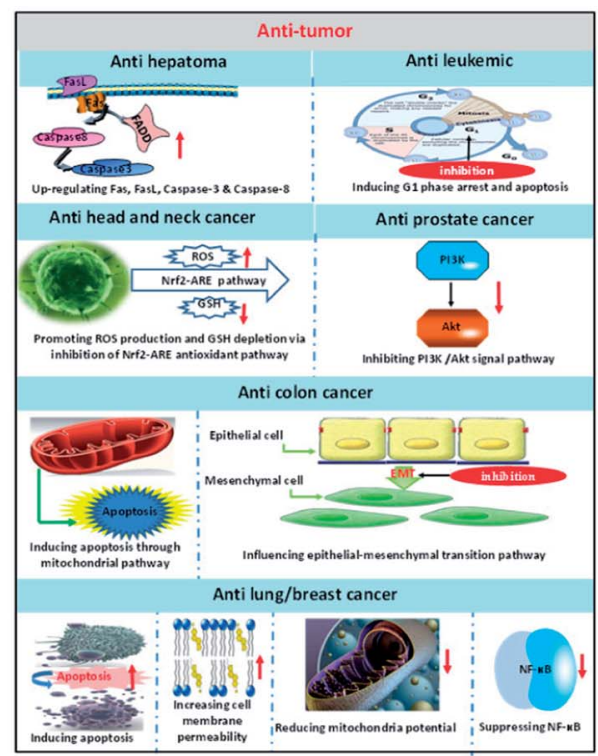

Fig. 8 Mechanisms of action of hederagenin.

to be discovered. Much of the present research has been confined to in vitro rather than in vivo studies; hence, whether HG is effective or sufficiently efficient in vivo is questionable and must be validated. In addition, while some knowledge has been gained regarding the mechanism of the anti-tumor activity of HG based on its ability to modulate diverse molecular signaling pathways involved in cancer, and to regulate a series of apoptosis related genes and mRNA and protein expression, knowledge of the mechanisms of the other known pharmacological activities of $\mathrm{HG}$ is limited and further investigation is needed. Regardless of the challenges mentioned above, the safety assessment is another critical concern worthy of more consideration. As mentioned previously, there is evidence that HG may be potentially toxic to animal species, other than rats and mice. However, the reason for this toxicity has not yet been addressed and the relationship between the dose and the toxicity is still unknown. Additionally, like most other triterpene saponins, HG also exhibits hemolytic activity correlated with its chemical structure, which limits its development as an injectable drug.

In view of the above challenges, the following strategies will be of great value in future research into the drug development and clinical application of HG. First, improving the bioavailability and extending the half-life of HG by adopting appropriate pharmaceutic or chemical methods. For instance, improving the solubility by using preparation technologies, such as micronization, solid dispersion, self-microemulsion, or inclusion technologies, thus improving its bioavailability. Developing a sustained- or controlled-release system by formulation design to maintain an effective blood concentration should decrease the administration frequency and side effects. Based on chemical-structure modifications, HG derivatives can be designed as prodrugs or prepared in the form of sodium salts. Second, from the point of view of the pharmacology and mechanism of action, further investigation of the potential unknown pharmacological activities of HG should expand the scope of its use. Meanwhile, more research into the mechanism of action will enable a better understanding of how HG works. Furthermore, a large number of in vivo studies should be conducted to validate its effectiveness, because a high sensitivity in vitro study does not necessarily represent the same result in vivo. Third, synthesizing novel derivatives by structural modification at the confirmed modification sites, or other potentially available sites of HG, to explore the potential for more promising agents with higher activity and better drug-like properties. Last, investigating the toxicological mechanisms of HG in animals other than rodents, elucidating the relationship between dosage and toxic effects, and decreasing or avoiding hemolysis by structure reorganization are desirable. In conclusion, the knowledge regarding HG has been growing rapidly in recent years, but there is still room for improvement in the understanding of its pharmacology, mechanism of action, and safety.

\section{Conflicts of interest}

These authors have no conflict of interest to declare.

\section{References}

1 J. W. Li and J. C. Vederas, Science, 2009, 325, 161-165.

2 H. J. Jung, C. O. Lee, K. T. Lee, J. Choi and H. J. Park, Biol. Pharm. Bull., 2004, 27, 744-747.

3 G. M. Woldemichael and M. Wink, J. Agric. Food Chem., 2001, 49, 2327-2332.

4 S. H. Lu, J. H. Guan, Y. L. Huang, Y. W. Pan, W. Yang, H. Lan, S. Huang, J. Hu and G. P. Zhao, Evid. Based Complement. Alternat. Med., 2015, 2015, 456354. 
5 Y. Chen, S. Y. Xi, Y. H. Teng, J. P. Li, Y. Y. Zhang, X. Zou, J. Y. Zhou, J. Wu and R. P. Wang, Chin. J. Exp. Tradit. Med. Formulae, 2016, 22(12), 133-138.

6 Y. Gao, C. He, W. Bi, G. Wu and E. Altman, Planta Med., 2016, 82, 171-179.

7 China, Active Ingredient Based on Hederagenin and Its Application in Medicines, CN 103830293 A, 2014.

8 Y. Gao, C. He, W. Bi, G. Wu and E. Altman, Planta Med., 2016, 82, 171-179.

9 China, Application of Hederagenin in the Preparation of Antitumor Drugs, CN 103463098 A, 2013.

10 X. Bai, B. S. Guan, M. Y. Liu, Q. S. Zhu, Y. He, P. J. Wang, Y. Wang and Q. W. Li, Lat. Am. J. Pharm., 2017, 36(1), 142-150.

11 X. Bai, B. S. Guan, M. Y. Liu, Q. S. Zhu, Y. He, P. J. Wang, Y. Wang and Q. W. Li, Lat. Am. J. Pharm., 2016, 35(7), 1509-1518.

12 Z. X. Zhao, Z. M. Zhao and C. G. Zhao, Pharmacol. Clin. Chin. Mater. Med., 2017, 33(1), 37-41.

13 L. Ding, Q. Hou, F. C. Xu, Q. Zhang, H. Wang and G. A. Liu, J. Northwest Norm. Univ., Nat. Sci., 2009, 45(1), 88-93.

14 E. H. Kim, S. Baek, D. Shin, J. Lee and J. L. Roh, Oxid. Med. Cell. Longevity, 2017, 2017, 5498908.

15 B. X. Liu, J. Y. Zhou, Y. Li, X. Zou, J. Wu, J. F. Gu, J. R. Yuan, B. J. Zhao, L. Feng, X. B. Jia and R. P. Wang, $B M C$ Complementary Altern. Med., 2014, 14, 412.

16 S. Y. Yin, R. P. Wang, X. Zhou and J. Wu, J. Tradit. Chin. Med., 2015, 56(7), 602-606.

17 D. Rodriguez-Hernandez, A. J. Demuner, L. C. Barbosa, R. Csuk and L. Heller, Eur. J. Med. Chem., 2015, 105, 57-62.

18 D. Rodriguez-Hernandez, A. J. Demuner, L. C. Barbosa, L. Heller and R. Csuk, Eur. J. Med. Chem., 2016, 115, 257267.

19 D. Rodriguez-Hernandez, L. C. A. Barbosa, A. J. Demuner, A. Nain-Perez, S. R. Ferreira, R. T. Fujiwara, R. M. de Almeida, L. Heller and R. Csuk, Eur. J. Med. Chem., 2017, 140, 624-635.

20 X. X. Liu, Y. T. Yang, X. Wang, K. Y. Wang, J. Q. Liu, L. Lei, X. M. Luo, R. Zhai, F. H. Fu, H. B. Wang and Y. Bi, Eur. J. Med. Chem., 2017, 141, 427-439.

21 China, Application and Preparation of Hederagenin for Treatment of Liver Cancer Drugs, CN 103948604 A, 2014.

22 B. X. Liu, R. P. Wang, X. Zou and J. Y. Zhou, J. Nanjing Univ. Tradit. Chin. Med., 2013, 29(1), 44-47.

23 B. X. Liu, R. P. Wang, X. Zou and J. Y. Zhou, Chin. J. Exp. Tradit. Med. Formulae, 2013, 19(4), 212-215.

24 S. R. Oh, K. Y. Jung, K. H. Son, S. H. Park, I. S. Lee, K. S. Ahn and H. K. Lee, Arch. Pharmacal Res., 1999, 22, 317-319.

25 G. J. Kim, D. H. Song, H. S. Yoo, K. H. Chung, K. J. Lee and J. H. An, Nutrients, 2017, 9, 41.

26 C. W. Lee, S. M. Park, R. Zhao, C. Lee, W. Chun, Y. Son, S. H. Kim, J. Y. Jung, K. H. Jegal, I. J. Cho, S. K. Ku, Y. W. Kim, S. A. Ju, S. C. Kim and W. G. An, Int. Immunopharmacol., 2015, 29, 528-537.

27 K. Takagi, E. H. Park and H. Kato, Chem. Pharm. Bull., 1980, 28, 1183-1188.
28 K. P. Bhargava, M. B. Gupta, G. P. Gupta and C. R. Mitra, Indian J. Med. Res., 1970, 58, 724-730.

29 S. J. Lee, E. J. Shin, K. H. Son, H. W. Chang, S. S. Kang and H. P. Kim, Arch. Pharmacal Res., 1995, 18(2), 133-135.

30 S. Y. Kim, K. H. Son, H. W. Chang, S. S. Kang and H. P. Kim, Arch. Pharmacal Res., 1999, 22, 313-316.

31 Z. L. Jin, N. Gao, D. Zhou, M. G. Chi, X. M. Yang and J. P. Xu, Pharmacol., Biochem. Behav., 2012, 100, 431-439.

32 B. F. Liang, Y. F. Cheng, T. Xue, H. B. Guo, X. Yuan and J. P. Xu, Medical Sciences, 2013, 4(37), 286-290.

33 D. Zhou, H. Jin, H. B. Lin, X. M. Yang, Y. F. Cheng, F. J. Deng and J. P. Xu, Pharmacol., Biochem. Behav., 2010, 94, 488-495.

34 B. F. Liang, F. Huang, H. T. Wang, G. H. Wang, X. Yuan, M. Z. Zhang, H. B. Guo, Y. F. Cheng and J. P. Xu, Pharm. Biol., 2015, 53, 368-377.

35 G. H. Wang, PhD thesis, Southern Medical University, 2013.

36 A. G. Wu, W. Zeng, V. K. Wong, Y. Z. Zhu, A. C. Lo, L. Liu and B. Y. Law, Pharmacol. Res., 2017, 115, 25-44.

37 China, The application of hederagenin in the preparation of anti-senile dementia drug, CN 102697791 A, 2012.

38 China, The derivative of hederagenin and its application in the preparation of drugs for the prevention and treatment of senile dementia, CN 105481935A, 2015.

39 China, The application of hederagenin in the preparation of anti-hyperlipidemia drug, CN 1385158A, 2002.

40 China, Preparation of hederagenin and its salt, CN 102659904A, 2012.

41 H. J. Park, D. H. Kim, J. W. Choi, J. H. Park and Y. N. Han, Arch. Pharmacal Res., 1998, 21, 24-29.

42 J. G. Luo, J. Liu and L. Y. Kong, Chem. Biodiversity, 2008, 5, 751-757.

43 China, Preparation and application of hederagenin, CN 101125880A, 2007.

44 B. Majester-Savornin, R. Elias, A. M. Diaz-Lanza, G. Balansard, M. Gasquet and F. Delmas, Planta Med., 1991, 57, 260-262.

45 D. Rodriguez-Hernandez, L. C. A. Barbosa, A. J. Demuner, R. M. de Almeida, R. T. Fujiwara and S. R. Ferreira, Eur. J. Med. Chem., 2016, 124, 153-159.

46 K. W. Hong, X. S. Jia, X. J. Yang, D. X. Dong and A. M. Department, Chin. J. Synth. Chem., 2017, 25(1), 18-25.

47 X. Yang, G. Li, L. Chen, C. Zhang, X. Wan and J. Xu, J. Chromatogr. B: Anal. Technol. Biomed. Life Sci., 2011, 879, 1973-1979.

48 E. W. Liu, J. L. Wang, L. F. Han, Y. X. Chang, T. Wang, Y. Huo, L. Wang and X. M. Gao, J. Nat. Med., 2014, 68, 488-497.

49 H. Zhang, F. Jing and Z. Zhang, Biomed. Chromatogr., 2017, 31(2), 1-8.

50 H. Zhu, L. Ding, S. Shakya, X. Qi, L. Hu, X. Yang and Z. Yang, J. Chromatogr. B: Anal. Technol. Biomed. Life Sci., 2011, 879, 3407-3414.

51 R. Zhang, H. Zhu, L. Ding and Z. Yang, J. Chromatogr. B: Anal. Technol. Biomed. Life Sci., 2014, 959, 22-26.

52 A. Sieben, L. Prenner, T. Sorkalla, A. Wolf, D. Jakobs, F. Runkel and H. Haberlein, Biochemistry, 2009, 48, 34773482. 
53 A. L. M. Albiero, M. H. Sarragiotto, A. Fujimura and E. M. Bacchi, Acta Farm. Bonaerense, 2001, 20(3), 169-171.

54 L. A. Yakovishin, V. I. Grishkovets and N. V. Tolkacheva, Chem. Nat. Compd., 2001, 37, 573-574.

55 Y. Lu, L. Yu, T. Zhu, N. Zhang, L. Chen and T. Hang, Chin. J. Pharm. Anal., 2012, 32, 1945-1949.

56 S. H. Zhong, Y. F. Wei, G. U. Rui, W. U. Yu and X. Duan, Lishizhen Med. Mater. Med. Res., 2010, 21(1), 6-7.

57 L. L. Fan, Z. Chen, Y. L. Feng, X. R. Li, Q. M. Xu and S. L. Yang, Chin. Tradit. Herb. Drugs, 2011, 42, 234-236.

58 H. Y. Han, C. J. Chu, S. Yao and J. Zhang, West China J. Pharm. Sci., 2013, 28(3), 241-243.

59 Y. Y. Liao and Y. P. Zhang, Journal of Guiyang College of Traditional Chinese Medicine, 2008, 30(3), 73-75.

60 T. Kuljanabhagavad, P. Thongphasuk, W. Chamulitrat and M. Wink, Phytochemistry, 2008, 69, 1919-1926.

61 Z. Q. Li, L. Luo and M. Ling, Chin. Tradit. Herb. Drugs, 1999, 30(6), 409-411.

62 L. I. Cai-Tang, H. Xie, D. Zhang and Y. X. Song, Chin. J. Exp. Tradit. Med. Formulae, 2013, 19(18), 145-147.

63 Y. B. Ou, M. J. Wei and H. Li, Chin. Tradit. Herb. Drugs, 2013, 44(14), 1872-1876.

64 Y. J. Yang, C. W. Sha and M. G. Chen, Chin. Pharm. J., 2011, 46(1), 11-13.

65 Y. Q. Zhao, L. X. Yang and X. M. Zhang, J. Chin. Med. Mater., 2008, 31(3), 465-470.

66 R. M. Shi and D. S. Geng, Pharm. J. Chin. People's Liberation Army, 2012, 28(3), 245-247.

67 G. H. Zheng, X. L. Pei, Y. Jin and L. Hui-Zi, J. Med. Sci., Yanbian Univ., 2012, 35(1), 30-32.

68 Y. Ding, D. Liu, F. Zhao, H. F. Tang and M. Zhao, Prog. Mod. Biomed., 2011, 11(8), 1569-1572.

69 D. Lan, X. U. Fu-Chun, W. Han and O. U. Qiao-Ming, J. Northwest Norm. Univ., Nat. Sci., 2007, 43(3), 62-65.

70 G. U. Zheng-Bing, G. J. Yang, H. Y. Cong, X. U. Yi-Xin, H. S. Chen and W. D. Zhang, Chin. Tradit. Herb. Drugs, 2002, 33(9), 781-782.

71 I. Dini, G. C. Tenore, O. Schettino and A. Dini, J. Agric. Food Chem., 2001, 49, 3976-3981.

72 S. G. Verza, F. Silveira, S. Cibulski, S. Kaiser, F. Ferreira, G. Gosmann, P. M. Roehe and G. G. Ortega, J. Agric. Food Chem., 2012, 60, 3113-3118.

73 A. M. Gomez-Caravaca, G. Iafelice, A. Lavini, C. Pulvento, M. F. Caboni and E. Marconi, J. Agric. Food Chem., 2012, 60, 4620-4627.

74 T. Kuljanabhagavad, P. Thongphasuk, W. Chamulitrat and M. Wink, Phytochemistry, 2008, 69, 1919-1926.

75 B. Didier, P. Cataldo, V. Alexis, M. S. Al-Nusairi, D. Ba, B. Joelle, H. Layth, M. I. Mohammed, M. Omurbek and O. Munira, Front. Plant Sci., 2016, 7, 1-18.

76 Y. Tang, X. Li, B. Zhang, P. X. Chen, R. Liu and R. Tsao, Food Chem., 2015, 166, 380-388.

77 V. Nowak, J. Du and U. R. Charrondiere, Food Chem., 2016, 193, 47-54.

78 R. J. Liu, H. Zhu, L. Ding, S. Shakya, Z. L. Yang and L. Cheng, China J. Chin. Mater. Med., 2013, 38, 2378-2383.
79 T. L. Hwang, C. C. Wang, Y. H. Kuo, H. C. Huang, Y. C. Wu, L. M. Kuo and Y. H. Wu, Biochem. Pharmacol., 2010, 80, 1190-1200.

80 J. Wang, X. Z. Zhao, Q. Qi, L. Tao, Q. Zhao, R. Mu, H. Y. Gu, M. Wang, X. Feng and Q. L. Guo, Food Chem. Toxicol., 2009, 47, 1716-1721.

81 H. J. Park, S. H. Kwon, J. H. Lee, K. H. Lee, K. Miyamoto and K. T. Lee, Planta Med., 2001, 67, 118-121.

82 V. Y. Chirva, P. K. Kintya, V. A. Sosnovskii, P. E. Krivenchuk and N. Y. Zykova, Chem. Nat. Compd., 1970, 6, 213-215.

83 D. H. Kim, K. W. Yu, E. A. Bae, H. J. Park and J. W. Choi, Biol. Pharm. Bull., 1998, 21, 360-365.

84 D. H. Kim, E. A. Bae, M. J. Han, H. J. Park and J. W. Choi, Biol. Pharm. Bull., 2002, 25, 68-71.

85 LookChem.com, Hederagenin, http://www.lookchem.com/ Hederagenin/.

86 B. Siewert, E. Pianowski, A. Obernauer and R. Csuk, Bioorg. Med. Chem., 2014, 22, 594-615.

87 R. Csuk, S. Schwarz, B. Siewert, R. Kluge and D. Stroehl, ChemInform, 2011, 42, 5256-5369.

88 R. Csuk, A. N. Barthel, A. Barthel, R. Kluge and D. Strohl, Eur. J. Med. Chem., 2010, 45, 3840-3843.

89 A. G. Wu, K. W. Wong, W. Zeng, L. Liu and Y. K. Law, Sci. Rep., 2015, 5, 17199.

90 S. H. Lu, J. H. Guan, Y. L. Huang, Y. W. Pan, W. Yang, H. Lan, S. Huang, J. Hu and G. P. Zhao, Evid. Based Complement. Alternat. Med., 2015, 2015, 456354.

91 R. B. Badisa, S. F. Darling-Reed, P. Joseph, J. S. Cooperwood, L. M. Latinwo and C. B. Goodman, Anticancer Res., 2009, 29, 2993-2996.

92 C. Bezivin, S. Tomasi, F. Lohezic-Le Devehat and J. Boustie, Phytomedicine, 2003, 10, 499-503.

93 K. P. Bhargava, M. B. Gupta, G. P. Gupta and C. R. Mitra, Indian J. Med. Res., 1970, 58, 724-730.

94 G. Gault, PhD thesis, University Claud Bernard Lyon 1, 1993.

95 Jolly Germany, Hedera helix, http:/www.goatworld.com/ health/plants/englishivy.shtml.

96 ASPCA, Toxic and Non-Toxic Plants, http://www.aspca.org/ pet-care/animal-poison-control/toxic-and-non-toxic-plants/ english-ivy.

97 AEC, Common Plants Toxic to Dogs and Cats, http:// www.aecvets.com.au/docs/Common-Plants-Toxic-to-Dogsand-Cats-NATIONAL.pdf.

98 Y. Gaillard, P. Blaise, A. Darre, T. Barbier and G. Pepin, J. Anal. Toxicol., 2003, 27, 257-262.

99 M. Soltani, K. Parivar, J. Baharara, M. A. Kerachian and J. Asili, Rep. Biochem. Mol. Biol., 2014, 3, 43-50.

100 E. Amini, M. Nabiuni, J. Baharara, K. Parivar and J. Asili, J. Coastal Life Med., 2014, 2, 762-768.

101 N. N. Q. Vo, E. O. Fukushima and T. Muranaka,J. Nat. Med., 2017, 71, 50-58.

102 C. Gauthier, J. Legault, K. Girard-Lalancette, V. Mshvildadze and A. Pichette, Bioorg. Med. Chem., 2009, 17, 2002-2008. 